\title{
Choosing a Control Group for Displaced Workers*
}

\author{
Pawel Krolikowski \\ Federal Reserve Bank of Cleveland
}

\begin{abstract}
The vast majority of studies on the earnings of displaced workers use a control group of never displaced workers to examine the effects of initial displacements. This approach attributes earnings declines due to all future job instability to the initial displacement event, overstating the losses relative to the average treatment effect. This paper's approach isolates the impact of an average displacement without conditioning on future displacement status in the control group. In comparisons of the standard and alternative approaches using PSID data, the estimated long-run earnings losses fall dramatically from 25 percent to as low as 5 percent.
\end{abstract}

\section{Keywords}

Displacement; earnings; control group

Job displacement, defined as an involuntary loss of job through layoff, business closure, or insufficient demand, affects many workers in the United States. According to the Displaced Worker Survey, from January 2011 through December 2013, 4.3 million workers were displaced from jobs they had held for at least 3 years. An additional 5.2 million were displaced from jobs they had held for less than 3 years (Bureau of Labor Statistics, 2014). A well-established literature documents that the earnings and wage losses of displaced workers are large and extremely persistent, remaining as long as 20 years after the displacement event. 1

Jacobson, LaLonde and Sullivan (1993b) (henceforth JLS) is a seminal paper in this literature. Using Pennsylvania administrative data for the years 1974 to 1986, JLS restricted their sample to workers with 6 years of tenure at the beginning of 1980 and further restricted their control group to workers who remain continuously employed from 1980 to 1986 . The vast majority of research published since JLS has followed a similar approach and used a

\footnotetext{
*I thank Michael W. L. Elsby, Brian P. McCall, Matthew D. Shapiro, Mel Stephens, and Dmitriy Stolyarov for many helpful conversations regarding this project. I am also grateful to Dionissi Aliprantis, John Bound, Sebastian Calonico, Patrick Coate, Bruce Fallick, Andrew Goodman-Bacon, Ashley Hajski, Andrew McCallum, Jeff Smith, and Isaac Sorkin for valuable comments. Meifeng Yang provided excellent research assistance. This project is, in part, funded by the University of Michigan's Rackham Graduate School Predoctoral Fellowship Program, the University of Michigan's Economics Department Robert Roosa Dissertation Fellowship, and NIA and NICHD grants to the Population Studies Center at the University of Michigan (T32 AG000221 and R24 HD041028, respectively). The content is solely the responsibility of the author and does not represent the views of the National Institutes of Health, the Federal Reserve Bank of Cleveland, or the Board of Governors of the Federal Reserve System.

Correspondence: pawel.krolikowski@ clev.frb.org.

${ }^{1}$ Earlier literature reviews include Hamermesh (1989), Fallick (1996), and Kletzer (1998). Recent work includes von Wachter, Song and Manchester (2009) and Davis and von Wachter (2011).
} 
control group of never displaced workers. ${ }^{2}$ One reason the literature has predominantly focused on this control group is to isolate the portion of earnings potential that is destroyed when an individual involuntarily loses a specific job. For this purpose it is natural to use a control group of workers who do not experience displacement and therefore do not lose this match-specific human capital.

Nevertheless, this paper argues that the standard approach may be somewhat misleading when it comes to estimating the average treatment effect (ATE) of displacement on subsequent earnings and the role of specific human capital. The use of a never displaced control group means that, even if the earnings effects of displacement are not long-lived, earnings declines from all future job instability will be attributed to the initial displacement event, thereby overstating the earnings losses associated with displacement. Put another way, this standard approach overstates (downward biased) the earnings losses of displaced workers relative to the ATE of being displaced.

This paper proposes an alternative approach that constructs the treatment group from individuals displaced in a particular year and the control group from individuals who do not experience a displacement in that year, without conditioning on events in other years. Compared to the standard approach, this alternative delivers an estimate for a different quantity: It estimates the effects of a job displacement relative to what would have happened had that displacement event not taken place in that year, allowing for the risk of job loss in other periods. I show that, in simulations where displacements do not raise the probability of subsequent job losses, this approach alleviates the major issues with the standard approach and delivers the ATE. When initial displacements raise the probability of future job losses, the alternative approach understates the earnings losses associated with displacement whereas the standard approach still provides an overestimate. Using simulation exercises, I derive an adjustment that can be used in empirical work to obtain a lower bound on the ATE, and I show that the standard approach dramatically overstates the earnings losses associated with displacement, especially several years after the displacement event. This study highlights that, even when the question being investigated is the role of specific human capital in earnings outcomes, the standard approach is inappropriate because it includes the downward bias highlighted above, thus overstating the role of specific human capital.

As with the simulations, empirical results using the Panel Study of Income Dynamics (PSID) point to a systematic tendency for the standard approach to yield estimates that, relative to the alternative approach, dramatically overstate the earnings losses following displacement. When one uses the method proposed by JLS, the PSID data suggest annual losses of around 25 percent, even 10 years after displacement, in line with previous estimates of earnings losses. The alternative approach yields losses of under 5 percent 10 years after displacement. The difference between the two sets of estimates is economically and statistically significant. The simulations provide a lower bound on the empirical ATE

\footnotetext{
${ }^{2}$ The analysis in the present paper applies equally well to research, such as Stephens (2001), that studies the consequences of first displacements using a control group of never displaced workers. The key issue with these approaches, as with the standard JLS approach, is that, for individuals in the control group, they condition on no displacements in future periods. Towards the end of this introduction, I discuss an approach by Stevens (1997) that looks at earnings losses since the most recent displacement. For a more thorough review of the recent literature, see Section 1.
} 
which implies earnings losses of under 10 percent 10 years after the displacement, far smaller than the losses implied by the standard approach.

JLS were aware of the distinction at the heart of the present paper. In their 1993 book (Section 4.1) they discussed this issue and were careful in how they defined their control group. Indeed, they mentioned that their estimates of the earnings consequences of displacement will tend to be larger than those using the alternative approach if the probability of displacement in other periods, conditioning on no displacement in the current period, is high. Furthermore, they mention that this was in fact the case in their 1980s Pennsylvanian data, where approximately 35 percent of the workers in their sample experienced a displacement (Chapter 4, Note 2). Unfortunately, JLS never investigated this issue further and as research on displaced workers has proceeded, these earlier concerns have largely faded and most researchers use a methodology similar to JLS without careful consideration. In many regards, the current paper explores the original remarks made by Jacobson, LaLonde and Sullivan (1993a). ${ }^{3}$

In addition to correctly estimating the earnings consequences of displacement, which is important in its own right, having an accurate and complete picture of the time-path of earnings around displacement serves to better inform and direct theoretical considerations aimed at explaining this phenomenon. ${ }^{4}$ As an example, if one documents a permanent reduction in earnings following displacement, as obtained with the standard approach in the PSID, this casts doubts on explanations appealing solely to specific human capital destruction or a loss in a particularly good-quality match, and grants more credence to stories focusing on loss of rents, information revelation or health effects. Similarly, documenting a persistent, but temporary, reduction in earnings following displacement, as obtained with the alternative approach in the PSID, brings human capital and matching explanations back into the picture. As researchers pursue the most promising theoretical frameworks to explain the earnings effects of displacement, it is important that the empirical benchmark is well understood and the ATE is correctly measured.

In contrast to much of the literature, Stevens (1997) presents an alternative approach to JLS. In that paper, Stevens documents the earnings losses since a worker's most recent displacement to highlight that multiple job losses explain much of the persistence in earnings losses following an initial displacement. This approach rules out subsequent displacements for both treated and control groups, thereby addressing the issue of future displacements among individuals in the treated group. The approach presented in this paper presents an alternative resolution which allows for future displacements in both the treated and control groups. Moreover, I show in Appendix A that, in simple simulated environments, this alternative approach delivers the ATE of displacement on earnings, whereas the approach taken by Stevens (1997) understates these losses. In this appendix I

\footnotetext{
${ }^{3}$ Fallick, Haltiwanger and McEntarfer (2012) are concerned about the difference between a control group of stayers and a control group of non-displaced separators. Consequently, they present earnings results for "all separators," "distressed separators," (job separators from firms undergoing large employment losses) and "job stayers." Flaaen, Sorkin and Shapiro (2015) use a control group of workers not displaced in a particular quarter. Neither paper compares the two approaches outlined in this paper using the same data. ${ }^{4}$ See Carrington and Fallick (2017) for a recent summary of the possible causes of earnings losses following displacement.
} 
also show that, when using observed data from the PSID, the approach using the most recent displacement delivers substantially smaller earnings losses than the alternative approach.

Davis and von Wachter (2011) (henceforth DvW) also take a different approach to measuring the earnings losses of displaced workers, an approach that I detail in Section 1. As with the approach taken by Stevens (1997), in Appendix A I show that, in simulated environments, this approach slightly understates the losses associated with displacement. In that appendix I also show that applying the approach in DvW to PSID data yields similar estimates of the earnings consequences of displacement as the alternative approach of this paper. Although the two approaches share some similarities, one of the key contributions of the present paper is to provide a careful comparison between the standard approach and the alternative approach using both simulated and observed data.

Jung and Kuhn (2016) is another closely related paper. That paper uses a search-andmatching model with a life-cycle component to deliver the earnings losses of displaced workers. For agents within their model, the authors demonstrate with theory that the JLS approach imposes an upward bias (a "selection effect") on the magnitude of displaced worker earnings losses. They attribute this upward bias to the fact that workers in the control group are selected because they do not experience future nonemployment. The current paper adds to this work by showing that Jung and Kuhn's critique of the standard approach matters not only in the context of their model, but also in observed data using the PSID.

Furthermore, the empirical results in the present paper suggest that conditioning on future outcomes in the control group is perhaps more relevant in empirical work than the model of Jung and Kuhn (2016) would suggest. I present evidence for this claim in Section 5.

In the empirical job training literature, Sianesi (2004) and Fredriksson and Johansson (2008) both address some of the present issues. In that context, unemployed individuals can participate in job training on an ongoing basis. As a result, selecting a control group of workers who never participate in job training may choose individuals who have left unemployment for a job. This amounts to conditioning on future (successful) outcomes in the control group. Sianesi mentions that this evaluation problem arises in ongoing programs "that individuals sooner or later will join provided they are still eligible..." The current paper highlights that estimating the effects of displacement is subject to a similar critique, and is broadly related to the literature on dynamic treatment effects, as in Heckman and Navarro (2007) and Lechner and Miquel (2010).

\section{Survey of Recent Displaced Worker Literature}

In addition to the papers highlighted in the previous section, Table 1 presents a list of the 14 most-cited papers in the displaced worker literature since 2001. The studies were selected based on a citation analysis in two major research databases, Google Scholar and Thomson Reuters Web of Science. In this table, I focus on economic outcomes, such as earnings, wages, re-employment probabilities and consumption.

The majority of the surveyed displaced worker papers use a control group of either workers who are never displaced or continuously employed throughout the observation period. Out 
of the 14 listed papers, 8 follow this method as their main approach. A couple of papers, such as Bender et al. (2002) and Farber (2005), in at least one of their approaches, do not use a control group, but simply look at differences among displaced individuals before and after the job loss. 5

A handful of papers, however, follow an approach that uses a control group of workers who are not displaced at a given point in time, similar to the alternative approach of this paper. I focus on DvW, but Eliason and Storrie (2006) and Mroz and Savage (2006) are two other examples that do not follow the standard approach. DvW are chiefly concerned with the cyclicality of earnings losses following displacement. To investigate this, the authors use Social Security Administrative data and create treated and control groups for each year, $y$, between 1980 and 2008. The treated group is composed of individuals displaced in $y, y+1$, and $y+2$, and the control group includes workers who remain with their employer in years $y$, $y+1$, and $y+2 .^{6}$ The authors estimate a distributed-lag model separately for each of these years and then average the coefficients from these regressions to report a final estimate.

The approach in the DvW paper is similar in spirit to the empirical approach followed in the present work, which is detailed in Section $4 .{ }^{7}$ However, among the papers in Table 1 that do not follow the standard approach, including DvW, Eliason and Storrie (2006), and Mroz and Savage (2006), none of them present sensitivity analyses to the choice of control group. ${ }^{8}$ One of the key contributions of the present paper is to provide a careful comparison, and highlight the dramatic differences in results, between the standard approach and the alternative approach using both simulated and observed data. Moreover, in Appendix A, I show that, unlike the alternative approach of this paper, in simulated environments, the approach taken by DvW slightly understates the losses associated with displacement. In that appendix I also show that applying the approach in DvW to PSID data yields similar estimates of the earnings consequences of displacement as the alternative approach of this paper.

\footnotetext{
5 In their main econometric approach, von Wachter, Song and Manchester (2009) use a control group of individuals who do not switch employers during 1974 to 1986 to analyze the consequences of displacement using data from 1974 to 2004. In a 2007 version of that paper (von Wachter, Song and Manchester, 2007, referring to Figure 4A), the authors note that "the gap between the earnings of separators and non-separators is largest relative to workers not leaving their employer from 1980 to 1985." The authors also mention that "It is not a priori clear which group of workers yields the ideal counterfactual earnings trend. The comparison with each different control group yields another answer to the question of the cost of job loss." Figure 4A of the 2007 version of that paper suggests that using a control group of workers that were not displaced in a given year would yield substantially smaller earnings losses following displacement than the control group of individuals who do not switch employers during 1974 to 1986.

${ }^{6}$ This approach is similar to the approach followed by Lafortune, Rothstein and Schanzenbach (2016) who use state-level variation in reform timing to study how post-1990 school finance reforms affect spending and achievement in low-income school districts. The same issue of multiple events arises in that context because many states have multiple legislative reforms over the observation period. For an approach similar to the one in Lafortune, Rothstein and Schanzenbach (2016), but in the context of job displacement, see Huttunen, Møen and Salvanes (2016).

${ }^{7}$ Mroz and Savage (2006) seem to share the motivation of the present paper when they say, “... For policy purposes, it may be more reasonable to ask what would happen if one could prevent a single spell of unemployment... rather than asking what would happen if one could forever banish unemployment." Moreover, Mroz and Savage (2006) explicitly mention that their results may differ from Kletzer and Fairlie (2003) because their approach "examine[s] what would happen if one were able to prevent a single spell of unemployment" as opposed to using a comparison group, "as is done in many displaced-worker studies, $\ldots$ of individuals who never experience a spell of unemployment."

${ }^{8}$ Chan and Stevens (2001) take a similar approach as in the present paper: “... This allows us to estimate the effects of displacement and to compare the employment patterns of displaced workers losing jobs at a given age with those of groups of workers who were employed at that age."
} 
Finally, although Table 1 focuses on economic outcomes, such as earnings, wages, reemployment probabilities and consumption, the use of the never displaced control group reaches beyond this scope. In particular, the vast majority of papers studying the effects of adult displacement on divorce, health-related measures, and even infant health or children's academic achievement, use a control group of never displaced workers. ${ }^{9}$

\section{Simulated Environments}

This section illustrates, by means of simple modeling exercises, the bias that can result from using a control group of never displaced workers to study the effects of initial displacements. It explores two distinct environments: a simple example where displacements affect future earnings but do not affect the future probability of displacement, and a more realistic example in which displacement persistently affects future earnings and the probability of subsequent displacements.

\subsection{Immediate Earnings Recovery}

Suppose that all workers receive an identical wage $w$ when employed, and a wage of zero when not employed. Suppose further that unemployed workers find a job with certainty but have to wait till next period to begin employment. Individual employment risk is governed by an exogenous separation shock which occurs with probability $\delta$ every period. This shock occurs before this period's payment, so individuals may receive zero earnings in more than one period consecutively: They lose a job, find a job with certainty, but experience the separation shock before they are paid in the new job. In this context, define "displacement" as the exogenous separation shock. In Section 2.1.1 and Section 2.1.2 I show, using conditional expectations and simulated data, respectively, how using a control of never displaced workers can result in biased estimates of the effect of displacement on earnings.

2.1.1 Conditional Expectations-Let time period 0 be the period of displacement, and let $k$ represent the time since displacement. Notice that the expected earnings of an individual in any given period are $(1-\delta) W$ since the worker earns $w$ with probability $(1-\delta)$ and zero with probability $\delta$. Then the time-path of earnings for individuals that experience displacement in period $0\left(D_{0}=1\right)$ in this simple model is:

$$
\begin{aligned}
& \mathbb{E}\left[e_{k} \mid D_{0}=1\right]=(1-\delta) w, \forall k<0 \\
& \mathbb{E}\left[e_{k} \mid D_{0}=1\right]=0, k=0 \\
& \mathbb{E}\left[e_{k} \mid D_{0}=1\right]=(1-\delta) w, \forall k>0
\end{aligned}
$$

The time-path of earnings for individuals not displaced at time 0 is:

\footnotetext{
${ }^{9}$ For an example studying divorce, see Charles and Stephens (2004); for health-related measures, see Sullivan and von Wachter (2009); for infant health, see Lindo (2011); and for children's academic achievement, see Stevens and Schaller (2011). Important exceptions when looking at health-related outcomes are Browning, Dano and Heinesen (2006) and Eliason and Storrie (2009).
} 


$$
\begin{aligned}
& \mathbb{E}\left[e_{k} \mid D_{0}=0\right]=(1-\delta) w, \forall k<0 \\
& \mathbb{E}\left[e_{k} \mid D_{0}=0\right]=w, k=0 \\
& \mathbb{E}\left[e_{k} \mid D_{0}=0\right]=(1-\delta) w, \forall k>0
\end{aligned}
$$

To obtain the treatment effect when using those not displaced at time 0 as the control group, subtract (2) from (1) to yield:

$$
\begin{aligned}
& \mathbb{E}\left[e_{k} \mid D_{0}=1\right]-\mathbb{E}\left[e_{k} \mid D_{0}=0\right]=0, \forall k<0 \\
& \mathbb{E}\left[e_{k} \mid D_{0}=1\right]-\mathbb{E}\left[e_{k} \mid D_{0}=0\right]=-w, k=0 \\
& \mathbb{E}\left[e_{k} \mid D_{0}=1\right]-\mathbb{E}\left[e_{k} \mid D_{0}=0\right]=0, \forall k>0
\end{aligned}
$$

Notice that this approach correctly predicts a treatment effect of $-W$ on impact, and no effect before and after displacement. In particular, this method correctly captures no long-run earnings losses due to displacement.

Now consider the empirical approach where the control group is made up of individuals who are never displaced, and the event is the first displacement. The time-path of earnings for those that are displaced at time 0 for the first time is as follows:

$$
\begin{aligned}
& \mathbb{E}\left[e_{k} \mid D_{0}^{\text {first }}=1\right]=w, \forall k<0 \\
& \mathbb{E}\left[e_{k} \mid D_{0}^{\text {first }}=1\right]=0, k=0 \\
& \mathbb{E}\left[e_{k} \mid D_{0}^{\text {first }}=1\right]=(1-\delta) w, \forall k>0
\end{aligned}
$$

Notice that these individuals have wage $w$ before the displacement because the event is their first displacement. The time-path for those never experiencing a separation is trivial:

$$
\mathbb{E}\left[e_{k} \mid N D=1\right]=w, \forall k
$$

To obtain the treatment effect with the standard approach, subtract (5) from (4), yielding:

$$
\begin{aligned}
& \mathbb{E}\left[e_{k} \mid D_{0}^{f i r s t}=1\right]-w=0, \forall k<0 \\
& \mathbb{E}\left[e_{k} \mid D_{0}^{\text {first }}=1\right]-w=-w, k=0 \\
& \mathbb{E}\left[e_{k} \mid D_{0}^{\text {first }}=1\right]-w=-\delta w, \forall k>0
\end{aligned}
$$

Notice that this approach correctly predicts $-W$ on impact (and zero in the periods before), but incorrectly predicts losses after the displacement event equal to $-\delta w$. The intuition is that each member of the treatment group experiences displacement with probability $\delta$ every 
period after displacement and that the never displaced control group never experience job loss.

2.1.2 Simulations-I simulate wage and employment data for 10,000 agents for a total of 200 periods and discard the first 100 periods to remove the effects of initial conditions. The probability of separation in a given period, $\delta$, is set to 0.15 , and I set the wage, $w$, to 10 . With this simulated data, I estimate JLS-type equations for earnings losses using the standard and alternative approaches discussed above.

The ATE of displacement in time period $k$ on wages in time period $k$ is

$$
\mathbb{E}\left[w_{k} \mid D_{k}=1\right]-\mathbb{E}\left[w_{k} \mid D_{k}=0\right]=0-w=-10
$$

where $D_{k}=1$ indicates a displacement in period $k$. The treatment effect does not vary with individual $i$ as there is no heterogeneity. Notice that the ATE of displacement in period $k$ on earnings in periods not equal to $k$ (denoted by $-k$ ) is

$$
\mathbb{E}\left[w_{-k} \mid D_{k}=1\right]-\mathbb{E}\left[w_{-k} \mid D_{k}=0\right]=\mathbb{E}\left[w_{-k}\right]-\mathbb{E}\left[w_{-k}\right]=0
$$

where the first equality follows from the fact that displacements have no persistent effect on earnings. In words, this equation says that there is no permanent wage reduction from job loss; unemployment events are exogenously stipulated, and when a worker finds a job, her wage is the same as before the separation event.

For both the alternative approach and the standard approach I estimate the following equation:

$$
w_{i t}=\alpha+\sum_{k=-6}^{10^{+}} D_{i t}^{k} \theta_{k}+\varepsilon_{i t}
$$

where $w_{i t}$ are earnings of individual $i$ at time period $t$ and $a$ is an intercept. In the alternative approach, $D_{i t}^{k}$ is a dummy variable that refers to any displacement event and is equal to 1 if individual $i$, at time period $t$, was displaced $k$ periods ago. Notice that since the displacement dummies refer to any displacement event, an individual that is displaced twice can have more than one dummy "on" at a particular time. For example, suppose someone gets displaced in periods $t=5$ and $t=10$. In period 8 , the individual has $D_{i, 8}^{3}=1$ and $D_{i, 8}^{-2}=1$.

Also notice that the specification pools the last dummy to include periods 10 or more years after a displacement. In the standard approach, I also estimate equation (9), but $D_{i t}^{k}$ is a dummy variable that refers to the first displacement event and is equal to 1 if individual $i$, at 
time period $t$, was displaced for the first time $k$ periods ago. Since the dummies refer to only one displacement event, only one dummy can be "on" at a particular time.

The "not-displaced-today" line in the top panel of Figure 1 presents the $\theta_{k}$ coefficients from estimating equation (9). The figure also shows the ATE in this example (equations (7) and (8)) and one can see that the alternative approach correctly predicts a treatment effect of $-W$ $=-10$ on impact, and no effect before and after the displacement event. This confirms the results using simple equations in Section 2.1.1. Intuitively, this approach takes into account all displacements and hence estimates the effects of an average displacement instead of the first displacement, as in the standard approach.

As an alternative, suppose we follow the standard JLS approach and use only the first displacement event, so that the $D_{i t}^{k}$ dummies in equation (9) refer only to the first displacement. With this approach the control group consists of individuals who are at least 6 years before their first displacement and hence, implicitly, includes no displaced individuals. The "never displaced" line in the top panel of Figure 1 presents the $\theta_{k}$ coefficients from estimating this alternative specification. Notice that this approach correctly gives $-W=10$ as the on-impact effect but incorrectly predicts losses equal to $-\delta W=0.15 \times 10=-1.5$ thereafter. Notice that the expected earnings of an individual in any given period are (1 $\delta) w$ since the worker earns $w$ with probability $(1-\delta)$ and zero with probability $\delta$. In this context, the standard approach overstates the long-run earnings losses by $\delta w=1.5$. This is precisely because the control group has not experienced displacement yet and the event that is being studied is the first displacement. The intuition is that the treatment group experiences displacement with probability $\delta$ every period after its first displacement, and the control group does not experience separations. As a result, the treated group appears to have permanently lower earnings following the displacement. Appendix B.1 presents an example where the true earnings recovery occurs with a one-period delay. This example suggests that the bias associated with the standard approach is larger when the displacement has a more persistent effect on earnings. Including individual fixed effects in this analysis does not alter any of these conclusions.

\subsection{Serially Correlated Displacements}

An important feature of the previous example is that the displacement probability, $\delta$, does not depend on past displacements. In this context, the alternative approach identifies the treatment effect of displacement on current and future earnings. However, as I show in Section 3.1, in observed data, workers who are displaced in a given period are more likely to be displaced in the future. If this increased likelihood of future displacement is causal, the alternative approach will tend to underestimate (upward biased) the ATE of displacement because it estimates the partial effect of displacement in a given period, holding future displacements fixed. As such, the alternative approach may underestimate the ATE in the short- to medium-run. In the context of persistent employment effects of displacement, the standard approach still overstates the earnings losses associated with displacement relative to the ATE. 
To be precise, to obtain the ATE in this more general context, I choose individuals who are displaced for the first time in period $k$ as the treated group, and individuals who have not experienced a displacement at or before period $k$, but could experience displacements after period $k$, as the control group. As such, the ATE of displacement on earnings in period $k$, $A T E_{k}$, is captured by:

$$
A T E_{k}=\mathbb{E}\left[e_{k} \mid D_{0}^{\text {first }}=1\right]-\mathbb{E}\left[e_{k} \mid D_{0}^{\text {first }}=0\right], \forall k
$$

where $e_{k}$ are the earnings in period $k$ and $D_{k}^{\text {first }}=1$ indicates a first displacement in period $k$. I want to emphasize that this concept of the ATE does not condition on displacement outcomes for the control group after period 0 . To investigate the magnitude of the bias associated with the alternative approach in this context, I perform an additional simulation exercise.

Appendix B.2 presents an economy where post-displacement earnings take one period to recover (the model in Appendix B.1) and assumes that the probability of displacement is elevated for one period after an initial displacement. Here I perform a more realistic simulation to measure the size of the upward bias associated with the alternative approach. In particular, I choose the effect of displacement on subsequent displacement probabilities to match the observed time-path of displacement probabilities after an initial displacement in the PSID (Figure 3, Section 3.1), and I choose the speed of the earnings recovery so that the coefficients from the alternative approach in the simulation resemble the recovery in earnings in the observed data (Figure 5, Section 5). I then find the difference between the coefficients of the alternative approach and the ATE in the simulation and use this as a measure of the upward bias associated with the alternative approach. Under the assumption that the observed serial correlation in displacements is entirely causal, this exercise provides an adjustment that can be applied to the coefficients from the alternative approach when using the observed data to obtain the ATE. If the observed serial correlation in displacements is not entirely causal, this adjustment will provide a lower bound on the ATE of displacement; a lower bound that is more restrictive than the lower bound provided by the standard approach.

Figure 2 provides the ATE of displacement in this economy, along with the results of estimating the standard and alternative approaches. One can see that, even under the assumption that future displacement effects are caused by the initial displacement event, the standard approach overstates the earnings losses associated with displacement, whereas the alternative approach provides an underestimate. In the data, the ATE will likely fall somewhere in between the results obtained by the alternative approach and the lower bound on the ATE effect because future displacements are likely not entirely driven by the initial displacement event. As such, I will use this simulation exercise to put tighter bounds on the ATE in the data. In particular, each year the 'ATE' line in Figure 2 is a convex combination of the standard and alternative approaches. In Section 5 I will use this vector of convex combinations in the observed data to obtain a similar line for a lower bound on the empirical ATE. 


\section{Data}

The empirical analysis uses an unbalanced panel version of PSID waves from 1968 to 2009, incorporating both the nationally representative sample and the poverty oversample. ${ }^{10}$ The strength of the PSID for this study is that workers have long histories, allowing precise estimation of individuals' fixed effects and individual time trends. The sample consists of household heads who, from their first observation as household heads, have at least three consecutive observations, and only observations for individuals between the ages of 18 and 65 are used. The final sample includes 10,830 household heads, with an average of 12 years of observations for each, yielding 133,059 observations.

Job displacements are determined from a question that asks respondents with low levels of current job tenure: "What happened to that employer (job)?" (the individual's previous job). The two categories of responses used to identify displacements are "plant closed/employer moved" and "laid off/fired." In the final sample, there are 6,746 displacements with 3,393 first displacements.

As explained in Stephens (2001), the year of displacement is measured with error in the PSID. The respondent's answers about earnings and employment refer to the previous calendar year. For the first 16 waves of the PSID, the survey asks what happened to the last job for those reporting a job tenure of less than one year. Subsequent surveys ask what happened to the previous job if the current job started on or after January 1 of the previous calendar year. Due to the timing of the interviews, job displacements may have occurred either during the previous calendar year or during the first few months of the current calendar year. For this study, a recorded displacement is assumed to have occurred during the survey year. Finally, household heads who report a displacement in the 1968 wave are excluded from the analysis because this displacement may have occurred any time in the 10 years prior to the survey. This follows the approach taken by Stevens (1997) and Stephens (2001, 2002).

\subsection{Summary Statistics and Displacement Probabilities}

Summary statistics for never displaced household heads and displaced household heads are presented in Table 2. Consistent with previous literature, displaced individuals tend to be younger than the never displaced at the time of the shock. Around 60 percent of household heads report never being displaced, and 40 percent report at least one displacement. The average annual displacement probability for the sample is 4.5 percent, which is similar to the numbers reported in Stevens (1997, Table 1) who also uses the PSID, and coincides with displacement rates from other sources (see, for example Kuhn, 2002, who concludes that they are between four and five percent for a broad set of countries, including the United States). The sample used in this study is predominantly male as the PSID definition of household head is, by default, the male, except under very rare circumstances.

\footnotetext{
${ }^{10}$ Both samples are used to increase sample size, and individual weights are used to maintain national representativeness and to deal with nonrandom attrition. The baseline results are similar with unweighted observations using only the nationally representative sample. The analysis excludes the Latino and immigrant supplement samples. Household-head-earnings data are available, using " $t-2$ " earnings information, for all years except 1997 and 1999.
} 
Figure 3 shows the average displacement probability following an initial displacement. This is used to calibrate the model in Section 2.2, and shows that the first displacement has implications for the likelihood of being displaced in the future. In particular, in the first couple of years after an initial displacement, the probability of displacement is above 10 percent, much higher than the average probability of displacement in the sample, which is 4.5 percent. The displacement probability remains high for several years, returning to the average displacement probability around 10 years after the initial displacement event.

Figure 4 plots, for every year $y$, the average displacement probabilities for individuals who experienced a displacement $y$ years ago and for those who did not experience a displacement $y$ years ago. The figure shows that those who are not displaced in a particular year are at risk of job loss in future periods. In the years after the event, nondisplaced workers have a persistent 3 to 4 percent probability of experiencing displacement. Although this is below the average probability of those who experience a displacement in year $y$, it is only slightly smaller than the average probability of displacement in the sample, which is 4.5 percent. In their book, Jacobson, LaLonde and Sullivan (1993a) mention that their approach may give substantively different results from the alternative approach of the present paper if the probability of displacement in other periods, conditioning on no displacement in the current period, is high. Figure 4 serves as evidence that this is the case in PSID data.

\section{Empirical Methodology}

Authors have used different specifications to assess the earnings losses of displaced workers. The standard approach focuses on the first displacement and, with some slight variations, takes the following form:

$$
e_{i t}=\alpha_{i}+\gamma_{t}+\lambda_{i} t+X_{i t} \beta+\sum_{k=-m_{l}}^{m_{u}^{+}} D_{i t}^{f i r s t, k} \theta_{k}+\varepsilon_{i t}
$$

where $e_{i t}$ are the annual earnings of household head $i$ at time $t, a_{i}$ and $\gamma_{t}$ represent individual and time fixed effects, respectively, $\lambda_{i}$ allow for individual linear time trends, and $D_{i t}^{\text {first }, k}$ equals one if individual $i$ was displaced for the first time $k$ periods ago at time $t . X_{i t}$ captures a quartic in worker age. The analysis treats those that are $m_{l}$ periods before their first displacement as part of the control group, and those who are $m_{u}$ or more years after their first displacement are captured in the last dummy variable. I set $m_{l}$ to 4 and $m_{u}$ to 11 . Here the ' + ' denotes that those who are $m_{u}$ periods or more after displacement are pooled to estimate the coefficient on the last dummy. Note that the control group for this regression consists of workers who do not experience a displacement in the relevant window because the control group is composed of individuals who are at least $m_{l}$ years before their first displacement. Alternatively, these are individuals who are not displaced yet. Similarly, the treatment group have no displacements before the event of interest, which is the first displacement. This specification finds its roots in JLS and has been used for decades in 
studies such as Stevens (1997), Stephens (2001), and Couch and Placzek (2010). I refer to this specification as the "never-displaced" specification.

I include observations with zero earnings in my analysis and report losses as a fraction of average earnings prior to displacement. Estimating the equations where observations with zero earnings are excluded does not alter the conclusions of this paper; however, these observations constitute a significant portion of the observations in my analysis. As an example, using the PSID sample in this paper, in 1980 about 8.5 percent of the sample report zero labor income in the previous year.

The alternative approach also uses equation (11) but instead of referring to the first displacement event it refers to any displacement. Mechanically, this means that the $D_{i t}^{k}$ dummies now refer to any displacement, not just the first displacement. As an example, if individual $i$ experiences displacement in 1980 and 1985, the dummy variables $D_{i, 1983}^{3}=1$ and $D_{i, 1983}^{-2}=1$. This makes clear that in a given year, for individuals who experience more than one displacement, more than one displacement dummy will be turned "on." As with the first specification, I express these losses as a fraction of the treatment group's average annual predisplacement earnings. I refer to this specification as the "not-displaced-today" specification. As I mention in Section 1, this approach is conceptually similar to the approach taken by Davis and von Wachter (2011), and Appendix A.2 shows that the two approaches deliver similar results when using the PSID data.

\section{Observed Displaced Worker Earnings Losses}

The standard and alternative approaches outlined in the previous section yield potentially different results. Using the PSID, I estimate both equations and present the results in Figure 5 , along with the 95 percent confidence interval for each approach. Standard errors are calculated using the percentile bootstrap approach. I bootstrap at the person level to preserve any serial correlation structure that the data might exhibit. The point-estimates here are the $\theta_{k}$ coefficients from equation (11) divided by the average earnings of the treatment group over the four years prior to initial displacement. ${ }^{11}$ With both approaches I use data from 1968 through 2009.

Looking at the point estimates, the two specifications paint a different picture of the earnings consequences for displaced workers. On impact, the standard and alternative approaches yield comparable estimates of earnings losses: around 30 percent. This suggests that the choice of empirical model is not crucial for the on-impact effect of displacement on earnings, although, as the intuitive examples suggest, the standard approach yields a larger on-impact effect. The recovery, however, is strikingly different for the two specifications. The alternative approach suggests a 20 percentage point earnings recovery in the 10 years

\footnotetext{
${ }^{11}$ To implement this regression I first-difference the data and then estimate the equation with an individual fixed effect and year dummies. This is preferred to double differencing the data to remove the individual fixed effect if the residuals from the estimated double-differenced equation are serially correlated (see Wooldridge (2002), Section 10.6.3). Estimating the equation $\Delta^{2} \hat{\varepsilon}_{i t}=\hat{\rho}_{1} \Delta^{2} \hat{\varepsilon}_{i, t}$ $-1+$ error ${ }_{i t}$ for the first-displacement approach yields $\hat{\rho}_{1}=-0.81(0.003)$. This suggests double-differencing the data is not appropriate.
} 
following displacement, with the earnings losses being indistinguishable from zero eight years after the displacement event. In contrast, the standard specification suggests that earnings remain permanently lower after displacement, showing little recovery even 10 years following the initial displacement event. As with the intuitive examples, the difference between the two estimates grows with the time since the displacement event. Although both empirical specifications point to tremendous costs associated with job displacement, the notdisplaced-today approach depicts a healthy recovery in earnings in the decade following displacement, whereas the never-displaced approach suggests a permanent decline in earnings. Using the adjustment derived in the simulations of Section 2.2, the lower bound on the ATE effect of displacement lies in between the standard and alternative approaches, and 10 years after the displacement event this lower bound suggests earnings losses of around nine percent.

As I mentioned in the introduction, Jung and Kuhn (2016) present a model which captures the notion that the standard JLS approach imposes an upward bias (a "selection effect") on the magnitude of displaced worker earnings losses. In their model they find that this selection implies that estimates using the standard approach overstate the earnings losses of displaced workers by around 30 percent six years after the displacement event. Figure 5 is broadly consistent with these theoretical findings, but suggests that the extent of this upward bias may be significantly larger in empirical work. In particular, the point estimates in Figure 5 suggest that six years after the displacement event the never-displaced approach overstates the earnings losses related to the lower bound on the average treatment effect by around 25 percent. However, relative to the not-displaced-today approach, the never-displaced approach overstates the earnings losses by a factor of around four or five.

The confidence intervals in Figure 5 are large, but they are not appropriate for performing statistical inference on the difference between the two approaches. Figure 6 plots the difference between the two approaches, with the 95 percent confidence interval calculated using the percentile bootstrap. As before, I bootstrap at the person level to preserve any serial correlation structure that the data might exhibit. In the short run the two approaches give earnings losses that are indistinguishable. At longer horizons, however, the standard approach implies larger earnings losses than the alternative approach, and the pointwise differences are statistically significant, except during the last two years. The point estimates suggest that the difference between the two approaches is just under 10 percentage points on impact, and grows to over 20 percentage points 10 years after the displacement event.

\section{Conclusion}

This paper highlights that there are different parameters of interest when estimating the earnings consequences of displacement, and that the use of different control groups can help uncover these different parameters. The standard approach, which has dominated the field, uses those not displaced during the whole period of observation as a control group, and focuses on the first displacement event. The alternative approach of this paper uses a control group of individuals who are not displaced in a particular year, but could be displaced in other years, and looks at any displacement. These two specifications identify different parameters and give dramatically different notions of the recovery of displaced worker 
earnings. Since displacements tend to affect earnings adversely, using those not displaced during the period of observation as a control group conditions on future (favorable) earnings outcomes. As such, the alternative approach of this paper identifies a parameter that may be more useful to researchers and policy-makers interested in the effect of displacement on workers' earnings.

In a simulated environment where displacements affect earnings adversely, but do not affect the probability of subsequent displacement, the alternative approach delivers the ATE of displacement on earnings and the standard approach overestimates these losses. When displacements raise the probability of future job loss, the alternative approach underestimates the earnings losses associated with displacement, but I compute an adjustment that can be used to derive a lower bound on the empirical ATE, and this lower bound is binding if future job losses are caused entirely by previous displacements. With these examples, the standard approach understates the earnings losses associated with displacement relative to this lower bound on the ATE.

Empirical results using the PSID confirm the findings from these simulations. In the PSID data, the standard approach yields annual earnings losses of around 25 percent, even 10 years after displacement. The alternative approach yields losses that are statistically indistinguishable from zero at the 10-year horizon. The differences in estimates between the two approaches are economically and statistically significant. Using the adjustment from the simulations, I provide a new lower bound on the ATE of displacement on earnings and find this to be under 10 percent 10 years after displacement, far closer to the estimate from the alternative approach. Intuitively, the standard approach yields significantly different results from the not-displaced-today approach when the incidence of the event is large and the event has a persistent effect on the outcome variable.

Although the present work has focused on the use of a never displaced control group when assessing the earnings consequences of job displacement, previous literature has used this control group to study the effect of displacement on a broad range of outcomes. As I mention in Section 1, these outcomes include consumption, divorce, health-related indicators, as well as the outcomes of children following their parents' displacement. Although a careful treatment of each of these outcomes is beyond the scope of the current paper, future research should consider different parameters of interest in each of these applications. In particular, for policy-makers, the more relevant counterfactual may be one that avoids displacement in a given period, and not one that avoids displacement forever. Moreover, the present paper may speak to a broader body of work using the event-study methodology with a control group who never experience the "event." The evidence presented here suggests that particular care is warranted in event-studies that estimate the long-run impact of treatment.

\section{References}

Bender StefanDustmann ChristianMargolis David N, Meghir Costas. Worker Displacement in France and Germany. In: Kuhn Peter J, editorLosing Work, Moving On: International Perspectives on Worker Displacement. Vol. Chapter 2. Kalamazoo, MI: W.E. Upjohn Institute for Employment Research; 2002. 375-470. 
Browning MartinDano Anne MollerHeinesen Eskil. Job displacement and stress-related health outcomes. Health Economics. 2006; 15(10):1061-1075. [PubMed: 16518795]

Burda Michael C, Mertens Antje. Estimating wage losses of displaced workers in Germany. Labour Economics. 2001; 8(1):15-41.

Bureau of Labor Statistics. Worker Displacement: 2011-2013. News release. 2014. USDL-14-1605. http://www.bls.gov/news.release/disp.nr0.htm

Carrington William J, Fallick Bruce C. Why Do Earnings Fall with Job Displacement?” Forthcoming in. Industrial Relations. 2017

Chan SewinStevens Ann Huff. Job Loss and Employment Partterns of Older Workers. Journal of Labor Economics. 2001; 19(2):484-521.

Charles Kerwin KofiStephens Melvin, Jr. Job Displacement, Disability, and Divorce. Journal of Labor Economics. 2004; 22(2):489-522.

Couch Kenneth A. Earnings Losses and Unemployment of Displaced Workers in Germany. Industrial and Labor Relations Review. 2001; 54(3):559-572.

Couch Kenneth A, Placzek Dana W. Earnings Losses of Displaced Workers Revisited. American Economic Review. 2010; 100:572-589.

Davis Steven J, von Wachter Till M. Recessions and the Costs of Job Loss. Brookings Papers on Economic Activity. 2011 Fall;(1):1-72. [PubMed: 28736453]

Eliason MarcusStorrie Donald. Lasting or Latent Scars? Swedish Evidence on the Long-Term Effects of Job Displacement. Journal of Labor Economics. 2006; 24(4):831-856.

Eliason MarcusStorrie Donald. Does Job Loss Shorten Life? Journal of Human Resources. 2009; 44(2):277-302.

Fallick Bruce C. A Review of the Recent Empirical Literature on Displaced Workers. Industrial and Labor Relations Review. 1996; 50(1):5-16.

Fallick BruceHaltiwanger JohnMcEntarfer Erika. Finance and Economics Discussion Series \#2012-73. Federal Reserve Board; Washington, DC: 2012. Job-to-Job Flows and the Consequences of Job Separations.

Farber Henry S. Industrial Relations Section Working Paper \#498. Princeton University; 2005. What Do We Know about Job Loss in the United States? Evidence from the Displaced Workers Survey, 1984-2004.

Flaaen AaronSorkin IsaacShapiro Matthew. Reconsidering the Consequences of Worker Displacement: Survey versus Administrative Measurements. 2015. Available at https://sites.google.com/site/ isaacsorkin/papers

Fredriksson PeterJohansson Per. Dynamic Treatment Assignment: The Consequences for Evaluation Using Observational Data. Journal of Business \& Economic Statistics. 2008; 26(4):435-445.

Hamermesh Daniel S. What Do We Know About Worker Displacement in the U.S.? Industrial Relations. 1989; 28(1):51-59.

Heckman James J, Navarro Salvador. Dynamic discrete choice and dynamic treatment effects. Journal of Econometrics. 2007; 136(2):341-396.

Huttunen KristiinaMøen JarleSalvanes Kjell G. Job Loss and Regional Mobility.” Forthcoming in. Journal of Labor Economics. 2016. Available at https://sites.google.com/site/krhuttunen/research

Jacobson Louis S, LaLonde Robert J, Sullivan Daniel G. The Costs of Worker Dislocation. Kalamazoo, MI: W.E. Upjohn Institute for Employment Research; 1993a.

Jacobson Louis S, LaLonde Robert J, Sullivan Daniel G. Earnings Losses of Displaced Workers. American Economic Review. 1993b; 83(4):685-709.

Jung PhilipKuhn Moritz. Earnings losses and labor mobility over the life-cycle. 2016. Available at https://sites.google.com/site/kuhnecon/

Kletzer Lori G. Job Displacement. Journal of Economic Perspectives. 1998; 12(1):115-136.

Kletzer Lori G, Fairlie Robert W. The Long-Term Costs of Job Displacement for Young Adult Workers. Industrial and Labor Relations Review. 2003; 54(4):682-698.

Kuhn Peter J. Summary and Synthesis. In: Kuhn Peter J, editorLosing Work, Moving On: International Perspectives on Worker Displacement. Vol. Chapter 1. Kalamazoo, MI: W.E. Upjohn Institute for Employment Research; 2002. 1-104. 
Lafortune JulienRothstein JesseSchanzenbach Diane Whitmore. School Finance Reform and the Distribution of Student Achievement. National Bureau of Economic Research Working Paper \#22011. 2016

Lechner MichaelMiquel Ruth. Identification of the effects of dynamic treatment by sequential conditional independence assumptions. Empirical Economics. 2010; 39(1):111-137.

Lindo Jason M. Parental job loss and infant health. Journal of Health Economics. 2011; 30(5):869879. [PubMed: 21798606]

Mroz Thomas A, Savage Timothy H. The Long-Term Effects of Youth Unemployment. Journal of Human Resources. 2006; 41(2):259-293.

Panel Study of Income Dynamics, public use dataset. Produced and distributed by the Survey Research Center, Institute for Social Research, University of Michigan, Ann Arbor, MI (2017).

Sianesi Barbara. An Evaluation of the Swedish System of Active Labor Market Programs in the 1990s. The Review of Economics and Statistics. 2004; 86(1):133-155.

Stephens Melvin, Jr. The Long-Run Consumption Effects of Earnings Shocks. The Review of Economics and Statistics. 2001; 83(1):28-36.

Stephens Melvin, Jr. Worker Displacement and the Added Worker Effect. Journal of Labor Economics. 2002; 20(3):504-537.

Stephens Melvin, Jr. Job Loss Expectations, Realizations, and Household Consumption Behavior. The Review of Economics and Statistics. 2004; 86(1):253-269.

Stevens Ann Huff. Persistent Effects of Job Displacement: The Importance of Multiple Job Losses. Journal of Labor Economics. 1997; 15(1):165-188.

Stevens Ann HuffSchaller Jessamyn. Short-run effects of parental job loss on children's academic achievement. Economics of Education Review. 2011; 30(2):289-299.

Sullivan Danielvon Wachter Till. Job Displacement and Mortality: An Analysis Using Administrative Data. The Quarterly Journal of Economics. 2009; 124(3):1265-1306.

von Wachter TillSong JaeManchester Joyce. Long-Term Earnings Losses Due to Job Separation During the 1982 Recession: An Analysis Using Longitudinal Administrative Data from 1974 to 2004. 2007. Available at https://academiccommons.columbia.edu/catalog/ac: 124303

von Wachter TillSong JaeManchester Joyce. Long-Term Earnings Losses due to Mass Layoffs During the 1982 Recession: An Analysis Using Longitudinal Administrative Data from 1974 to 2004. Department of Economics, Columbia University; 2009.

Wooldridge Jeffrey M. Econometric Analysis of Cross Section and Panel Data. The MIT Press; 2002.

\section{A Appendix: A Comparison to Stevens (1997) and Davis and von Wachter (2011) (For Online Publication)}

In this appendix I present results from two approaches that are related to the present work. Using the PSID, Stevens (1997) documents the earnings losses since a worker's most recent displacement. Using Social Security Administrative data, Davis and von Wachter (2011) (henceforth DvW) create treated and control groups for every year in their data, a process I outline in more detail in Section 1. In simulated environments, both approaches underestimate the ATE of displacement, but in distinct ways. When applied to the PSID data, the approach of DvW yields similar earnings losses to the alternative approach of this paper. The approach of Stevens (1997) delivers far smaller earnings losses than the alternative approach of this paper. 


\section{A.1 Simulations}

\section{A.1.1 The Approach of Stevens (1997)}

This section outlines the bias that can result when using the most recent displacement as the event as opposed to the first displacement or any displacement as in the standard and alternative approaches, respectively. This is one of the methods used by Stevens (1997). I use the simple economy in Section 2.1 where individuals experience an immediate earnings recovery.

The top panel of Figure 7 shows the results from estimating equation (9) where the dummies refer to the most recent displacement. Intuitively, now the control group are individuals who are at least more than 6 years before their most recent displacement and thus this includes displaced individuals. This means that the control group have earnings of $(1-\delta) W=8.5$ because some of them are out of work and have no earnings. Prior to their most recent displacement, the treated also have displacements so the estimated effect is zero. On impact, displaced workers only lose $(1-\delta) W=8.5$ because the control group have average earnings of 8.5. After their most recent displacement, the treated group have no more displacements and, since the control group do experience subsequent displacements, the earnings actually rise above zero to $\delta w=1.5$. The true long-run earnings effects of displacement in this simple example is zero. In this sense, using the most recent displacement as the event can understate the earnings losses associated with displacement. In Section A.2 I present evidence from the PSID that corroborates the findings of this simple exercise.

\section{A.1.2 The Approach of Davis and von Wachter (2011)}

This section presents simple intuition for the method used in DvW and shows that this approach slightly understates the earnings losses associated with displacement. These authors pick a particular year, $y$. The treatment group is composed of individuals displaced in year $y$ and the control group is composed of individuals not displaced in year $y$. The displacement dummies are created so that $D_{i t}^{k}$ is zero for all $t$ and all $k$ for the control group, and for the treatment group equal to 1 if individual $i$, at time period $t$ was displaced $k$ periods ago and zero otherwise.

This approach is similar to the not-displaced-today approach outlined in the main text and equations (1) and (2) can be used for the time-path of earnings for the displaced and notdisplaced, respectively, when the earnings recovery is immediate. However, with this approach, those not displaced this period are the control and since these individuals have all their dummies turned to zero, the constant in equation (9) is $w(1-\delta)$ as opposed to $w$ in the not-displaced-today approach. Moreover, there is nothing in the procedure that allows the earnings of the control group to be different in the treatment period since all their dummies are set to zero. In this sense, although the control group are individuals who are not displaced this period, the way the estimation is operationalized means that the intercept of equation (9) refers to an average worker (who may or may not be employed) since the control group can experience displacements outside of year $y$ that are not picked up by the $D_{i t}^{k}$ dummies. The bottom panel of Figure 7 shows the $\theta_{k}$ coefficients from estimating 
equation (9) for an arbitrary year with this DV approach when the earnings recovery is immediate. On-impact the earnings losses are $w(1-\delta)=8.5$, and zero in all other periods.

\section{A.2 Comparisons Using the PSID}

Figure 8 shows the results from estimating earnings losses in the PSID with four different methods: a) The not-displaced-today approach in this paper; b) the never-displaced approach used by JLS; c) the approach in DvW; and d) one of the approaches in Stevens (1997) (since the most recent displacement). The figure supports the results from the simulations in Appendix A.1. In particular, the approach in DvW yields similar estimates of the earnings consequences of displacement to the alternative approach in this paper. The approach that uses the most recent displacement, as in Stevens (1997), yields losses following displacement that are dramatically smaller. The gap between this approach and the notdisplaced-today approach grows with time since displacement and 10 years after the displacement event, this approach implies earnings gains from displacement of around 20 percent. The simulations in Appendix A.1 provide intuition for why this might be the case.

\section{B Appendix: Other Simulated Environments (For Online Publication)}

This appendix presents additional numerical examples. The example in Appendix B.1 builds on the example in Section 2.1 by imposing that earnings take one period to recover after displacement. Appendix B.2 presents a simpler case of the model in Section 2.2. It takes the economy in Appendix B.1 and adds one period of employment effects after an initial displacement.

\section{B.1 One-Period Delay in Earnings Recovery}

Perturb the example in Section 2.1 in only one way: suppose that the true earnings recovery is $0.5 \mathrm{~W}$ (conditional on employment) in the period after displacement and then back to $W$ two periods after displacement (conditional on employment). In other words, displacement has a short-lived impact on earnings, but the long-run earnings losses are still exactly zero. In the next two sections I compare the results using the standard and alternative approaches using conditional expectations and simulations.

\section{B.1.1 Conditional Expectations}

In this simple environment, the expected wage for an individual who is employed (with probability $(1-\delta))$ in a given period is:

$$
\mathbb{E}[w \mid e m p]=0.5 w \delta+w(1-\delta)
$$

This is because an employed individual can either be employed or unemployed last period. She experiences unemployment last period with probability $\delta$ and this period will have wage $0.5 \mathrm{w}$. Alternatively she was not unemployed last period with probability $(1-\delta)$ and earns $W$ this period because she is at least two periods after any potential displacement.

The time-path of earnings for those displaced at time period 0 is as follows: 


$$
\begin{aligned}
& \mathbb{E}\left[e_{k} \mid D_{0}=1\right]=(1-\delta) \mathbb{E}[w \mid e m p], \forall k<0 \\
& \mathbb{E}\left[e_{k} \mid D_{0}=1\right]=0, k=0 \\
& \mathbb{E}\left[e_{k} \mid D_{0}=1\right]=(1-\delta) 0.5 w, k=1 \\
& \mathbb{E}\left[e_{k} \mid D_{0}=1\right]=(1-\delta) \mathbb{E}[w \mid e m p], \forall k>1
\end{aligned}
$$

because the individual is not employed at time $k=0$ and then, conditional on employment in the next period, receives $0.5 \mathrm{~W}$. The time-path of earnings for individuals not displaced at time 0 is:

$$
\begin{aligned}
& \mathbb{E}\left[e_{k} \mid D_{0}=0\right]=(1-\delta) \mathbb{E}[w \mid \text { emp }], \forall k<0 \\
& \mathbb{E}\left[e_{k} \mid D_{0}=0\right]=(1-\delta) w+0.5 w \delta=\mathbb{E}[w \mid \text { emp }], k=0 \\
& \mathbb{E}\left[e_{k} \mid D_{0}=0\right]=(1-\delta) w, k=1 \\
& \mathbb{E}\left[e_{k} \mid D_{0}=0\right]=(1-\delta) \mathbb{E}[w \mid \text { emp }], \forall k>1
\end{aligned}
$$

In the period of displacement the individual is guaranteed to be employed, but with probability $\delta$ she was unemployed last period and therefore only obtains $0.5 \mathrm{~W}$ in period 0 , and with probability $(1-\delta)$ she was employed last period and earns $W$ in period 0 . In period 1 , the individual was employed last period, and therefore earns $w$ if she is employed.

To obtain the treatment effect when using those not displaced at time 0 as the control group, subtract (14) from (13) to obtain:

$$
\begin{aligned}
& \mathbb{E}\left[e_{k} \mid D_{0}=1\right]-\mathbb{E}\left[e_{k} \mid D_{0}=0\right]=0, \forall k<0 \\
& \mathbb{E}\left[e_{k} \mid D_{0}=1\right]-\mathbb{E}\left[e_{k} \mid D_{0}=0\right]=-\mathbb{E}[w \mid e m p], k=0 \\
& \mathbb{E}\left[e_{k} \mid D_{0}=1\right]-\mathbb{E}\left[e_{k} \mid D_{0}=0\right]=-0.5 w(1-\delta), k=1 \\
& \mathbb{E}\left[e_{k} \mid D_{0}=1\right]-\mathbb{E}\left[e_{k} \mid D_{0}=0\right]=0, \forall k>1
\end{aligned}
$$

Notice that the approach (correctly) predicts a treatment effect of $-\mathbb{E}[\mathrm{w} / \mathrm{emp}]$ on impact, a treatment effect of $-0.5 w(1-\delta)$ in the period after displacement, and no effect in other periods. ${ }^{12}$ In particular, this method correctly captures no long-run earnings losses due to displacement, and estimates the treatment effect on impact relative to workers who are employed, but not necessarily employed for more than one period. This is the treatment effect of interest because the treated individual is not necessarily employed for more than one period.

${ }^{12}$ The ATE of a separation is $-\mathbb{E}[w / e m p]$ on impact, since we are comparing the wage of a separated worker to the average employed worker. 
Now consider the empirical approach where the control group is made up of individuals who are never displaced, and the event is the first displacement. The time-path of earnings for those that are displaced at time 0 for the first time is as follows:

$$
\begin{aligned}
& \mathbb{E}\left[e_{k} \mid D_{0}^{f i r s t}=1\right]=w, \forall k<0 \\
& \mathbb{E}\left[e_{k} \mid D_{0}^{f i r s t}=1\right]=0, k=0 \\
& \mathbb{E}\left[e_{k} \mid D_{0}^{f i r s t}=1\right]=(1-\delta) 0.5 w, k=1 \\
& \mathbb{E}\left[e_{k} \mid D_{0}^{f i r s t}=1\right]=(1-\delta) \mathbb{E}[w \mid e m p], \forall k>0
\end{aligned}
$$

To obtain the treatment effect with this approach, subtract (5) from (16), which yields:

$$
\begin{aligned}
& \mathbb{E}\left[e_{k} \mid D_{0}^{\text {first }}=1\right]-w=0, \forall k<0 \\
& \mathbb{E}\left[e_{k} \mid D_{0}^{\text {first }}=1\right]-w=-w, k=0 \\
& \mathbb{E}\left[e_{k} \mid D_{0}^{\text {first }}=1\right]-w=-0.5 w(1+\delta), k=1 \\
& \mathbb{E}\left[e_{k} \mid D_{0}^{\text {first }}=1\right]-w=-0.5 w \delta(3-\delta), \forall k>0
\end{aligned}
$$

Notice that the outcome predicts $-W$ on impact, and losses of $-0.5 w(1+\delta)$ in period $k=1$ (as opposed to $-0.5 w(1-\delta)$ ) and long-run losses of $0.5 w \delta(\delta-3)<0$ in all future periods. So this method incorrectly predicts long-run earnings losses, for the same reason as before. Moreover, notice that the earnings losses predicted using this method are larger than in the previous scenario where the recovery in earnings was immediate. ${ }^{13}$

\section{B.1.2 Simulations}

In this one-period delay environment, the expected wage for an individual who is employed (with probability $(1-\delta)$ ) in a given period is:

$$
\mathbb{E}[w \mid e m p]=0.5 w \delta+w(1-\delta)=9.25
$$

This is because an employed individual can either be employed or unemployed in the last period. She experiences unemployment in the last period with probability $\delta$, and this period will have a wage of $0.5 \mathrm{w}$. Alternatively, she is not unemployed in the last period with probability $(1-\delta)$ and earns $w$ this period because she is at least two periods after any potential displacement.

In this simple example, the ATE of displacement in time period $k$ on wages in time period $k$ is

\footnotetext{
${ }^{13}$ In fact, the long-run earnings losses appear to be larger the more protracted the actual earnings recovery.
} 


$$
\mathbb{E}\left[w_{k} \mid D_{k}=1\right]-\mathbb{E}\left[w_{k} \mid D_{k}=0\right]=0-\mathbb{E}[w \mid e m p]=-9.25
$$

The treatment effect of displacement in time period $k$ on wages in time period $k+1$ is

$$
\mathbb{E}\left[w_{k+1} \mid D_{k}=1\right]-\mathbb{E}\left[w_{k+1} \mid D_{k}=0\right]=[\delta \cdot 0+(1-\delta) 5]-[\delta \cdot 0+(1-\delta) 10]=-4.25
$$

where $\mathbb{E}\left[w_{k+1} / D_{k}=1\right]$ is equal to the expected earnings of an individual displaced last year. That is, with probability $\delta$ this person earns nothing in period $k+1$ because they are displaced again, and with probability $(1-\delta)$ they earn 5 because they were separated last period. By similar reasoning one can find the expression for $\mathbb{E}\left[w_{k+1} / D_{k}=0\right]$, which is equal to the expected earnings of an individual not displaced last year. Notice that in all periods other than $k$ and $k+1$, the ATE of displacement is zero because earnings losses persist for only one period.

The "not-displaced-today" line in Figure 9 shows the results of estimating equation (9) with any displacement as the event. ${ }^{14}$ On impact the earnings losses are exactly $-9.25(=\mathbb{E}[\mathrm{w} /$ emp]), and in the period after displacement, they are $-4.25(=-0.5 w(1-\delta))$. This method correctly captures the fact that there are no long-run earnings losses due to displacement.

The "never displaced" line in Figure 9 also shows the $\theta_{k}$ coefficients from estimating equation (9) with the first displacement as the event. Notice that this approach correctly predicts no effect before displacement but incorrectly implies a treatment effect of $-W=-10$ on impact. In the period just after displacement, the model predicts earnings losses of -5.75 $(=-0.5 w(1+\delta))$, and, strikingly, losses of $-2.14(=-0.5 w \delta(3-\delta))$ thereafter. These are both inflated compared to the actual losses: $-4.25(=-0.5 w(1-\delta))$ and 0 , respectively. This method incorrectly predicts long-run earnings losses for the same reasons as before: a never displaced control group and no prior displacements in the treatment group. Notice that, compared to the case where earnings recover immediately, the long-run earnings losses are even greater when the actual earnings recovery is more protracted $(2.14>1.5)$.

\section{B.2 Serially Correlated Displacements: One-Period Employment Effects}

This exercise takes the economy in Section B.1 (where post-displacement earnings take one period to recover) and assumes that the probability of separation is $\delta^{+}=0.3$ in the period after displacement and then, conditional on no separation, is back to $\delta=0.15$ two periods after displacement. This introduces persistent effects of displacement on future employment and is a pre-cursor to the model in Section 2.2 of the main text where there are both persistent earnings and employment effects of displacement. To obtain the ATE in this context, I choose individuals who are displaced for the first time in period $k$ as the treated group, and individuals who have not experienced a displacement at or before period $k$, but

\footnotetext{
${ }^{14}$ In this exercise, similar to Stevens (1997), I remove agents who are unemployed in the first period and those who were unemployed in the period before the sample starts.
} 
could experience displacements after period $k$, as the control group (equation (10) in the main text).

Figure 10 plots the average earnings difference between these two groups, in addition to the estimated coefficients from the standard and alternative approaches. Notice that on impact, the standard approach captures the ATE and the alternative approach underestimates the ATE. From the ATE we can see that the employment effect takes about two periods to resolve itself and during that time the alternative approach understates the earnings losses associated with displacement and the standard approach overstates these losses. Once the employment effects of the initial separation subside, the alternative approach captures the ATE and the standard approach continues to provide an overestimate of the earnings losses. 


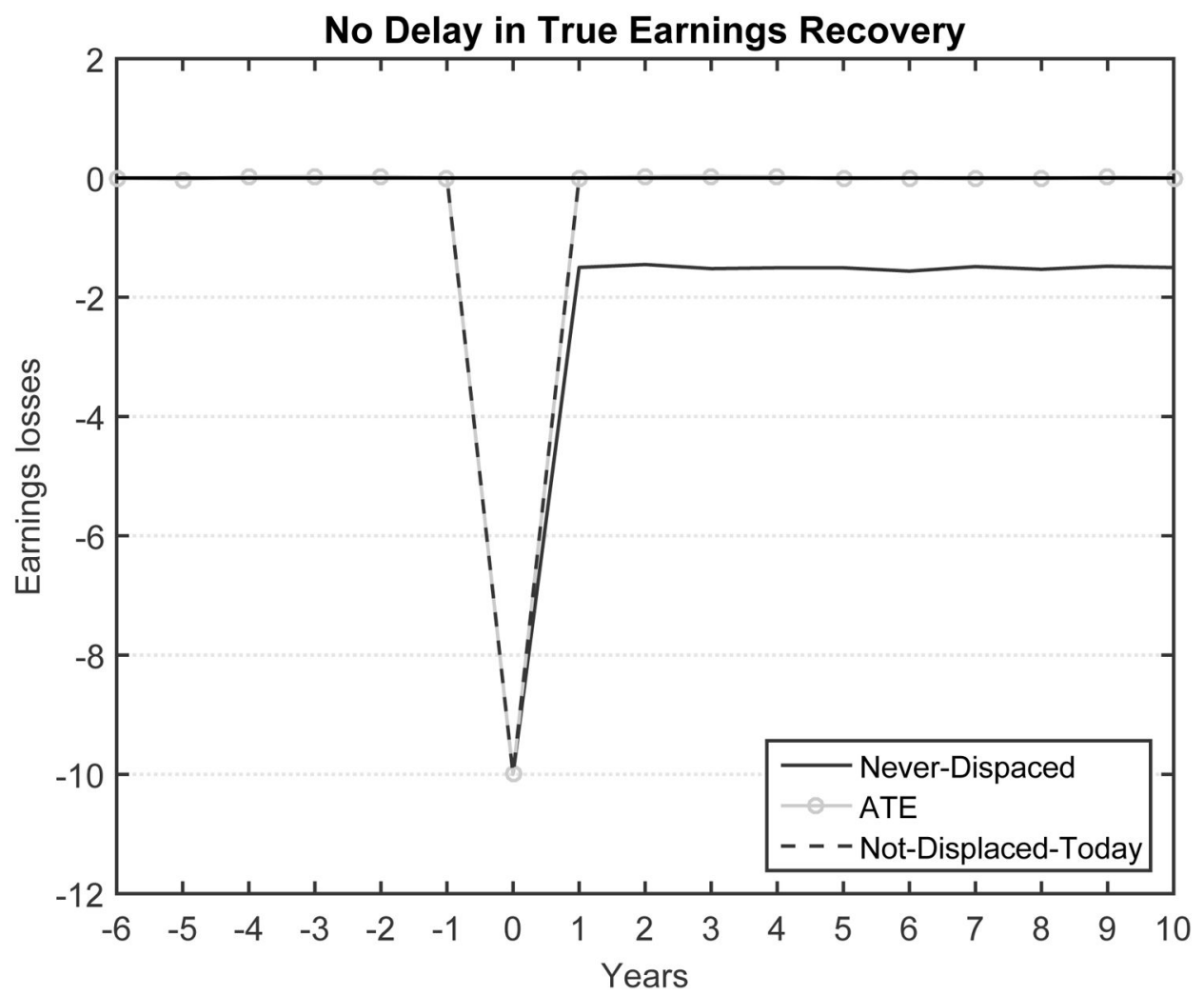

Figure 1.

Simulation Results: Never-Displaced and Not-Displaced-Today Approaches Note: In the example where the earnings recovery following job loss is immediate (Section 2.1 ), the never-displaced approach overstates the long-run earnings losses by $\delta w=1.5$. The not-displaced approach correctly predicts an on-impact effect of $-W=-10$ and long-run earnings losses of zero. 


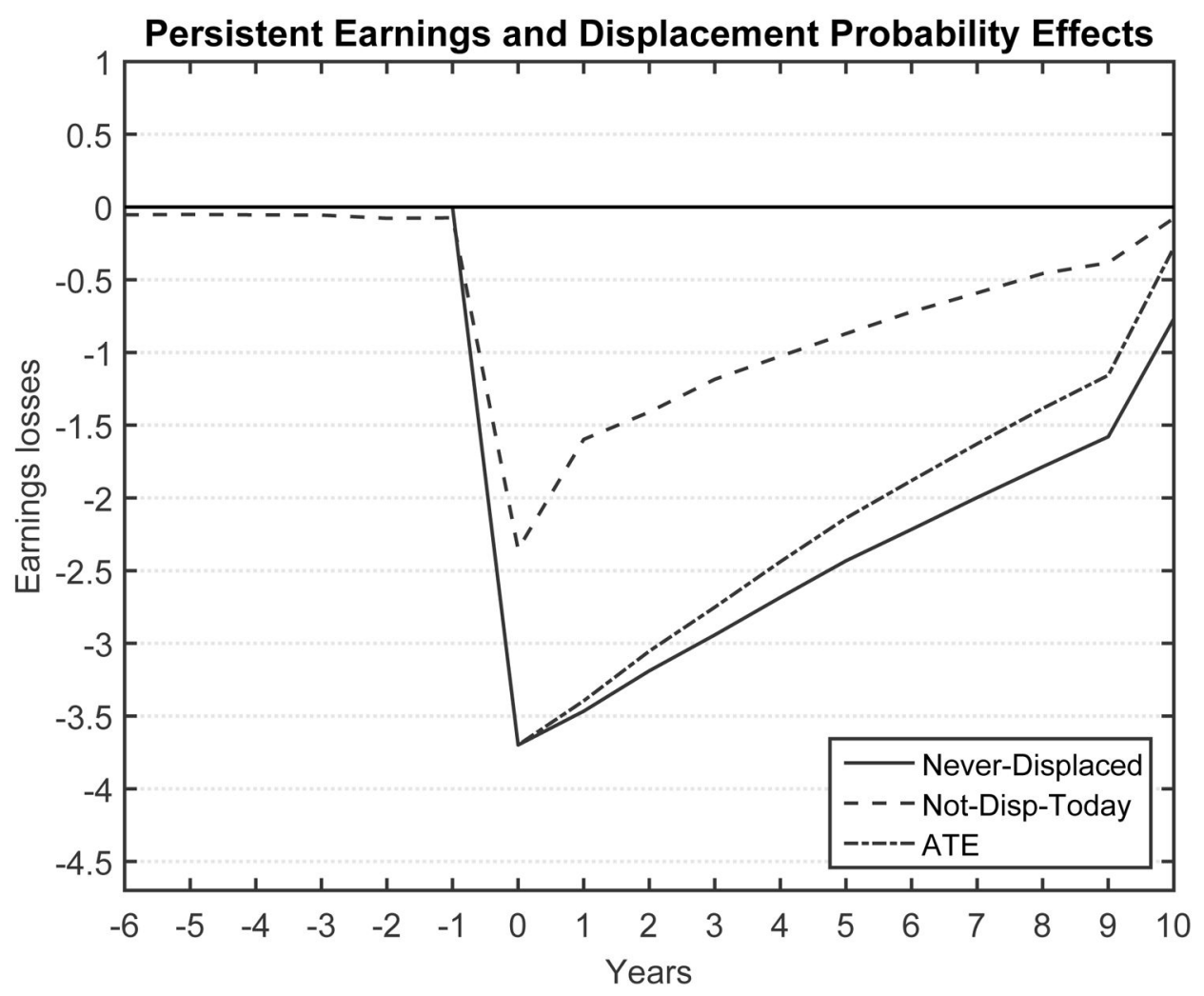

Figure 2.

Simulations with Serially Correlated Displacements

Note: When displacement has persistent effects on earnings and subsequent displacement probabilities (Section 2.2), the ATE lies between the estimates provided by the alternative and never displaced approaches. In the long-run, however, the not-displaced-today approach is close to the ATE. See Section 2.2 for how the parameters governing this simulation and the ATE are calculated in this context. If initial displacements cause future displacements (by assumption in this simulation), the 'ATE' line provides the ATE. 


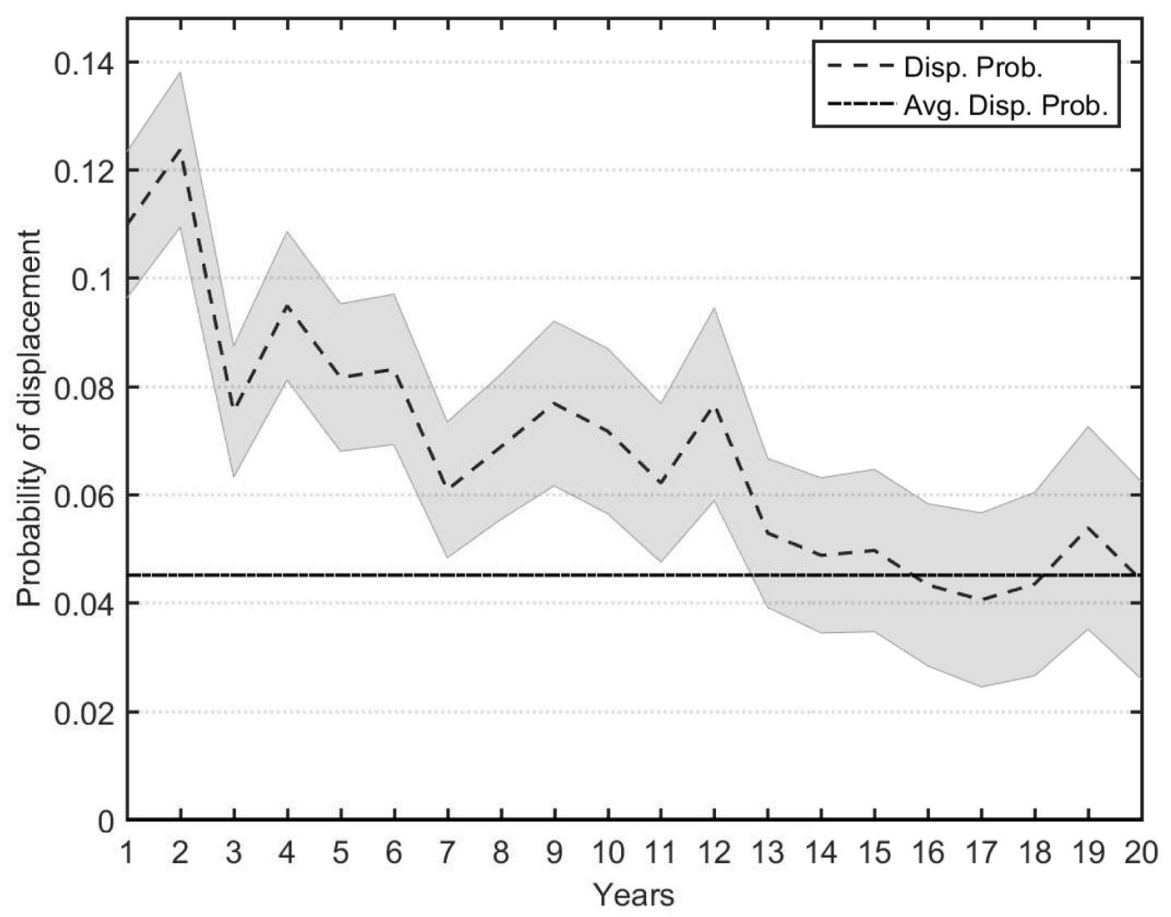

Figure 3.

Probability of Displacement After the First Displacement Using PSID Data

Note: The probability of displacement is above 10 percent in the first two years after the first displacement event and remains elevated for over 10 years. The initial rise in the probability of displacement is large relative to the average probability of displacement in the sample which is 4.5 percent. This figure shows the probability of a displacement subsequent to an initial displacement relative to the average displacement probability in the PSID sample. The shaded region corresponds to 95 percent confidence interval. This time-path of displacement probabilities (after smoothing with lowess) is matched in the simulation exercise in Section 2.2 . 


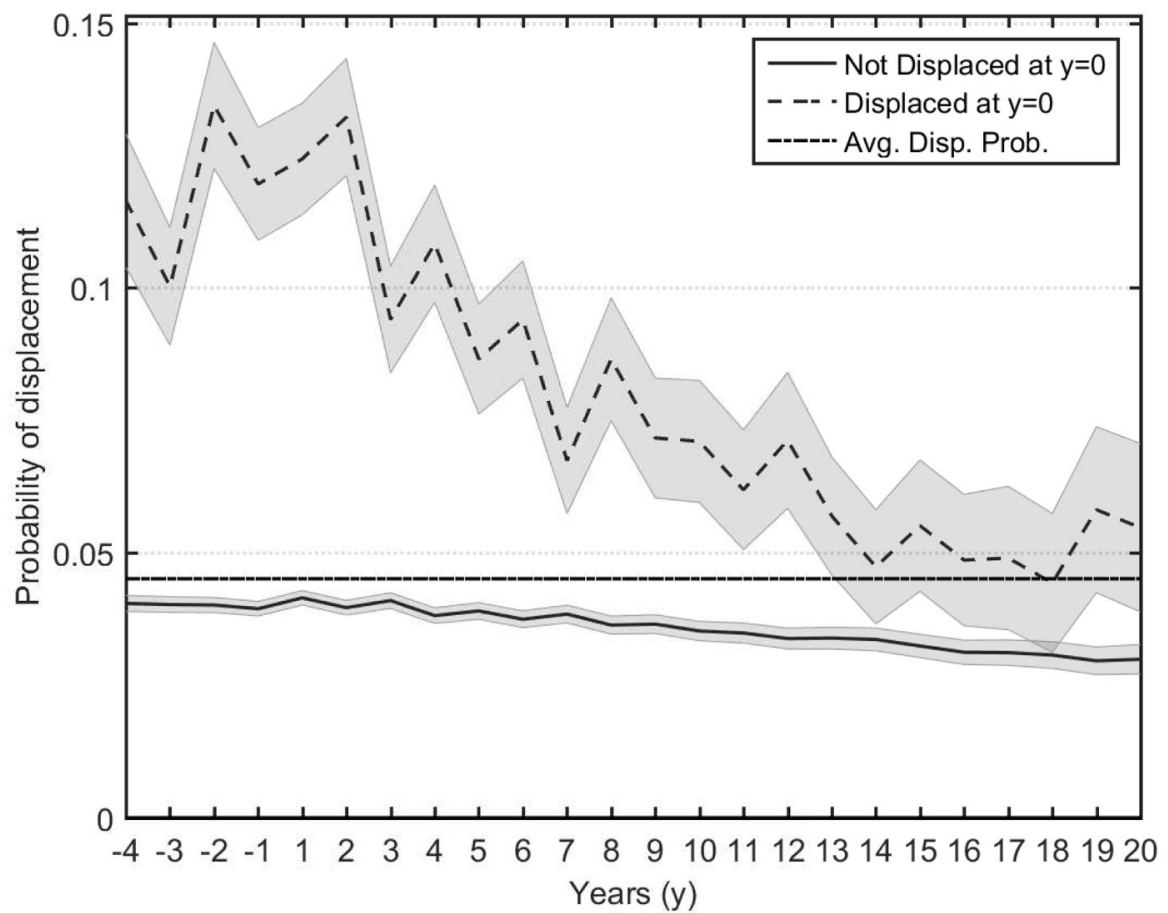

Figure 4.

Future Displacement Probabilities for those Displaced and Not Displaced In the Past Using PSID Data

Note: Those not displaced in the past have a significant probability of displacement in future years. This figure shows the probability of displacement for individuals displaced $y$ years ago and not displaced $y$ years ago in the PSID. The shaded regions correspond to 95 percent confidence intervals. I omit year ' 0 ' because for those displaced in year $y$ this probability is one and for those not displaced in year $y$ this probability is zero. 


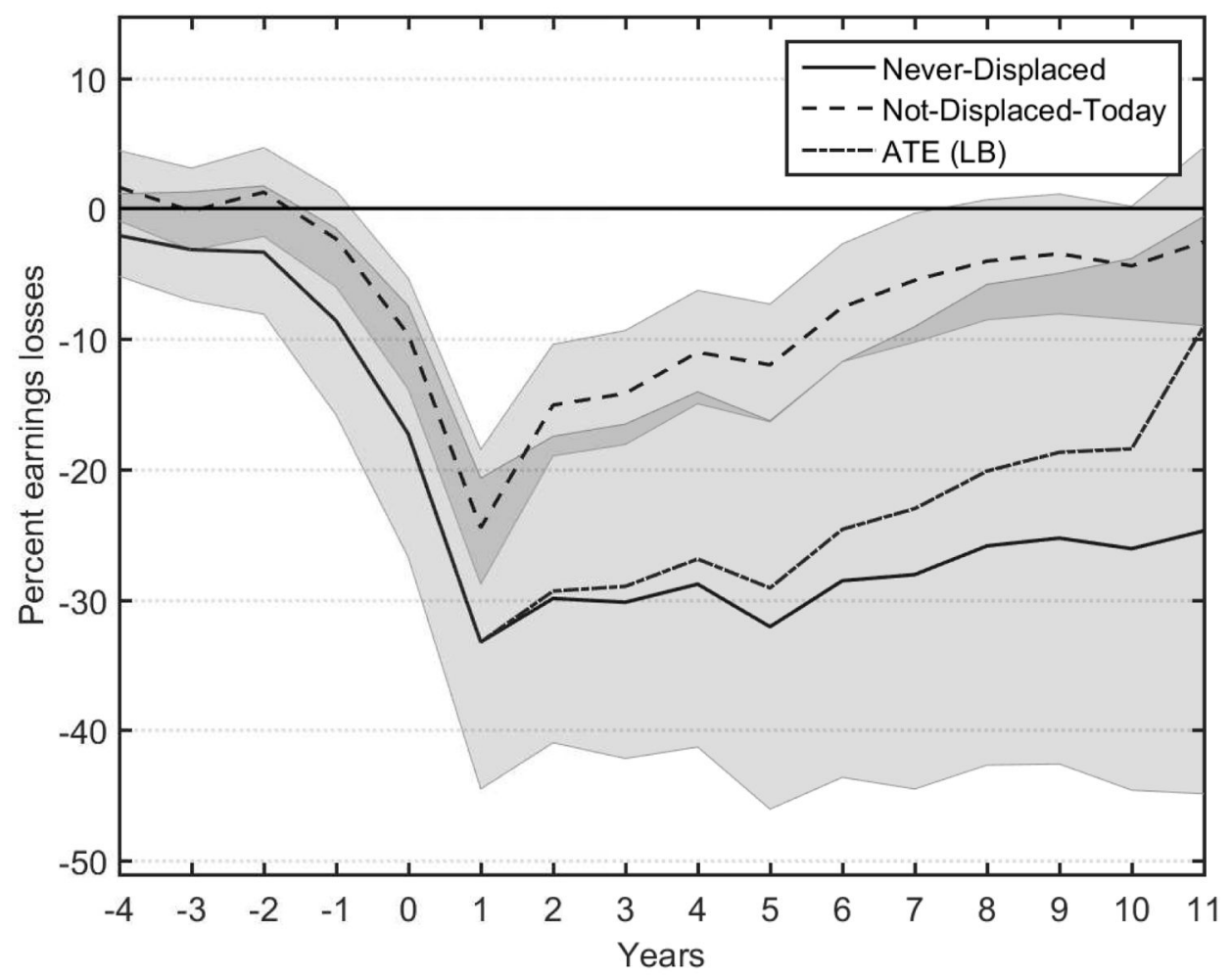

Figure 5.

Effect of Displacement on Head's Income: Never Displaced versus Not-Displaced-Today Specifications Using PSID Data

Note: The estimated long-run earnings losses fall dramatically from 25 percent when using the standard approach to under 5 percent when using the alternative approach. Using the simulation results from Section 2.2, the lower bound on the ATE is obtained by taking the appropriate convex combination between the never displaced and not-displaced-today coefficients. This 'ATE (LB)' line is the ATE if subsequent displacements are caused by an initial displacement; otherwise, this line acts as a lower bound for the ATE. Both the never displaced and not-displaced-today equations include dummies four years before the displacement shock and 11+ years after the displacement shock. For definitions of the control groups in the never displaced and not-displaced-today approaches, see Section 4. The analysis applies individual weights from the PSID, but the results are similar with unweighted observations using only the Survey Research Center (SRC) sample. The shaded regions correspond to 95 percent confidence intervals, with standard errors computed using the bootstrap method with 1,000 replications (percentile bootstrap). 


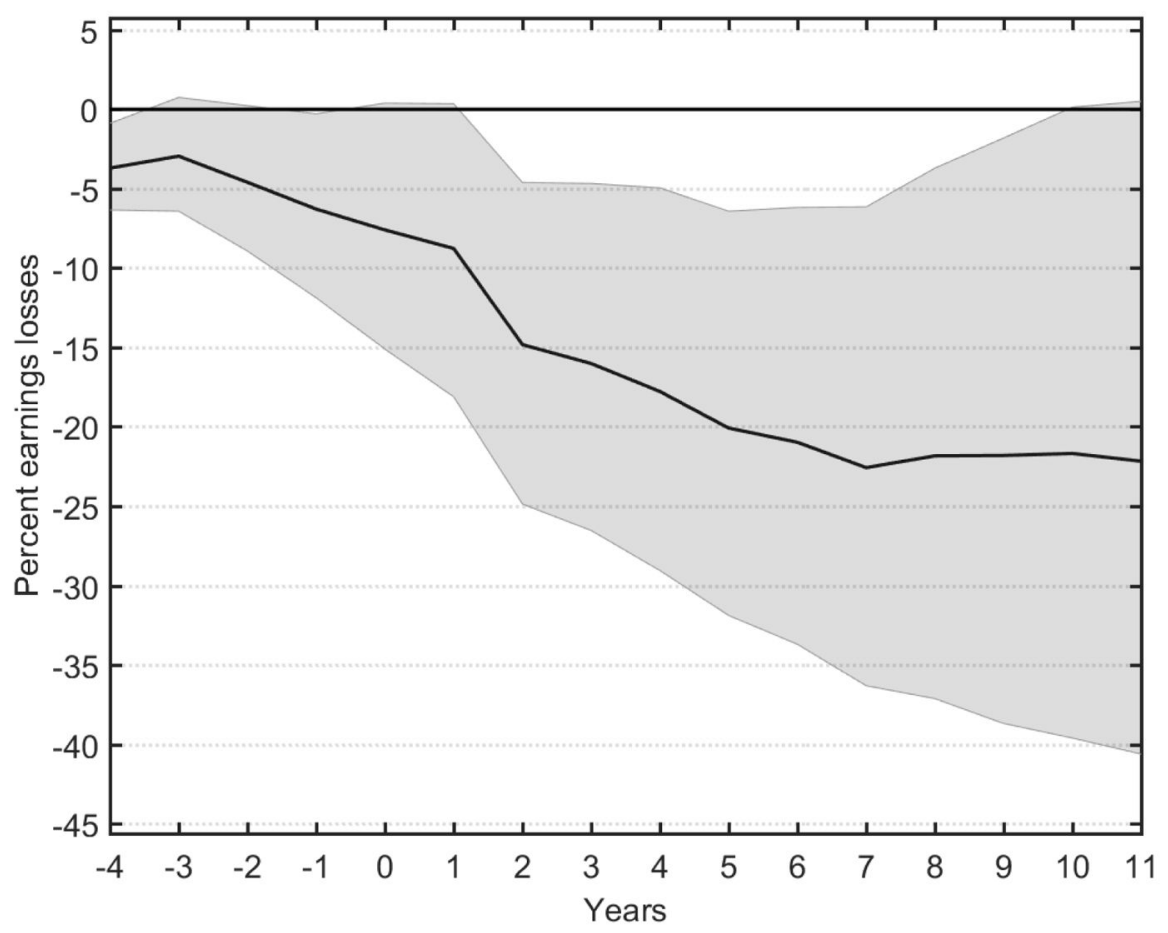

Figure 6.

Bootstrapped Confidence Interval for Difference Between Never Displaced and Not-

Displaced-Today Specifications

Note: The difference between the never displaced and not-displaced-today approaches is economically and statistically significant at longer horizons. The solid line is the difference between the never displaced and not-displaced-today approaches as in Figure 5. The shaded region represents the bootstrapped 95 percent confidence interval (percentile bootstrap). I bootstrap at the person level to preserve any serial correlation structure that the data might exhibit. I use 1,000 bootstrap replications. 

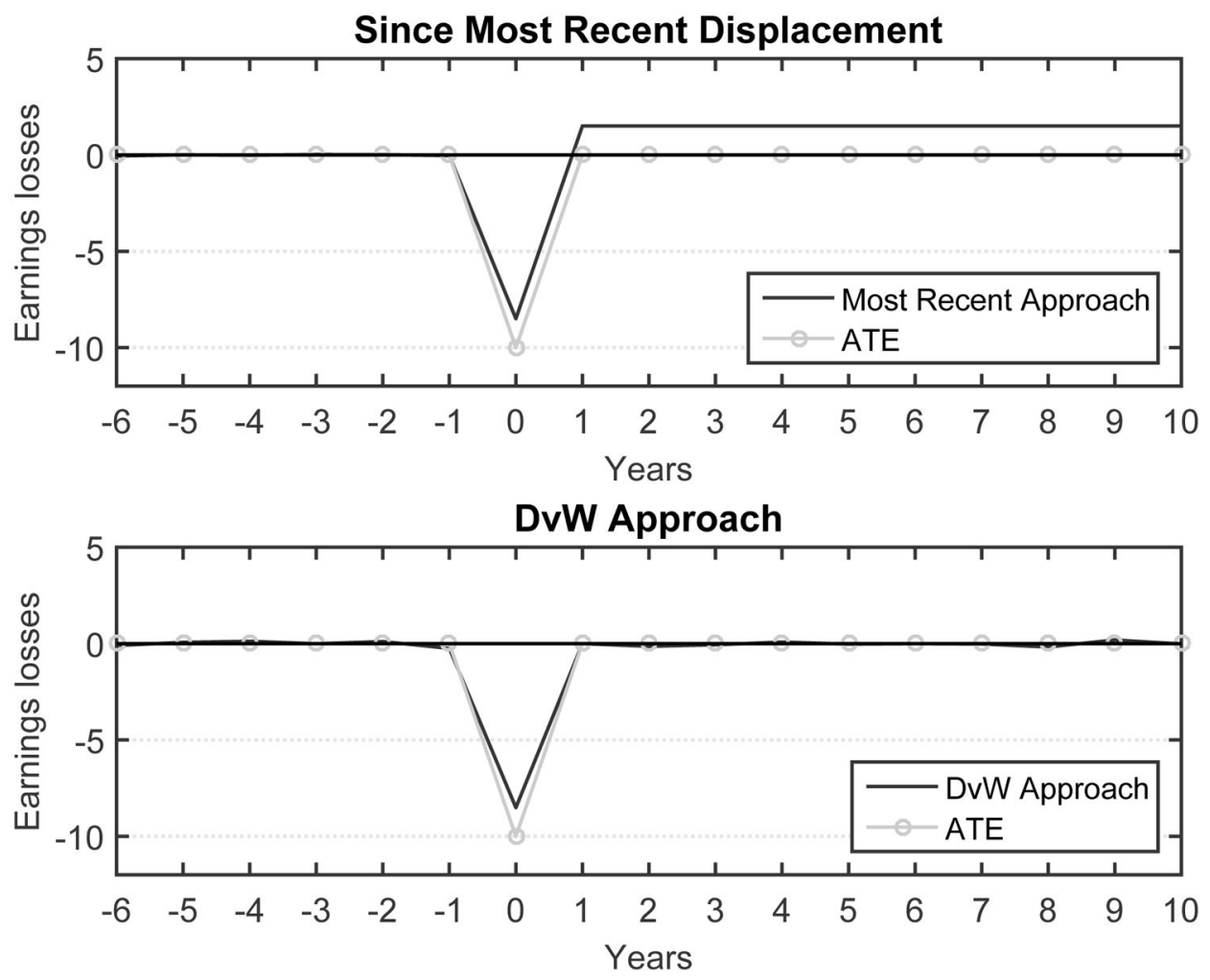

Figure 7.

No Delay in True Earnings Recovery: Since-Last-Displacement and DvW Approaches Note: The top panel shows that looking at the most recent displacement event understates earnings losses after displacement by a factor of $\delta W=1.5$. This exercise estimates equation (9) using the most recent displacement as the event in the simple simulation with an immediate recovery in earnings (Section 2.1). This is one of the approaches used by Stevens (1997). The bottom panel shows that using the approach in Davis and von Wachter (2011) underestimates the earnings losses from displacement slightly in the short-run. The underestimate on-impact is by a factor of $\delta w=1.5$. To see the results for this simulation from the alternative approach and the standard approach, see Figure 1. 


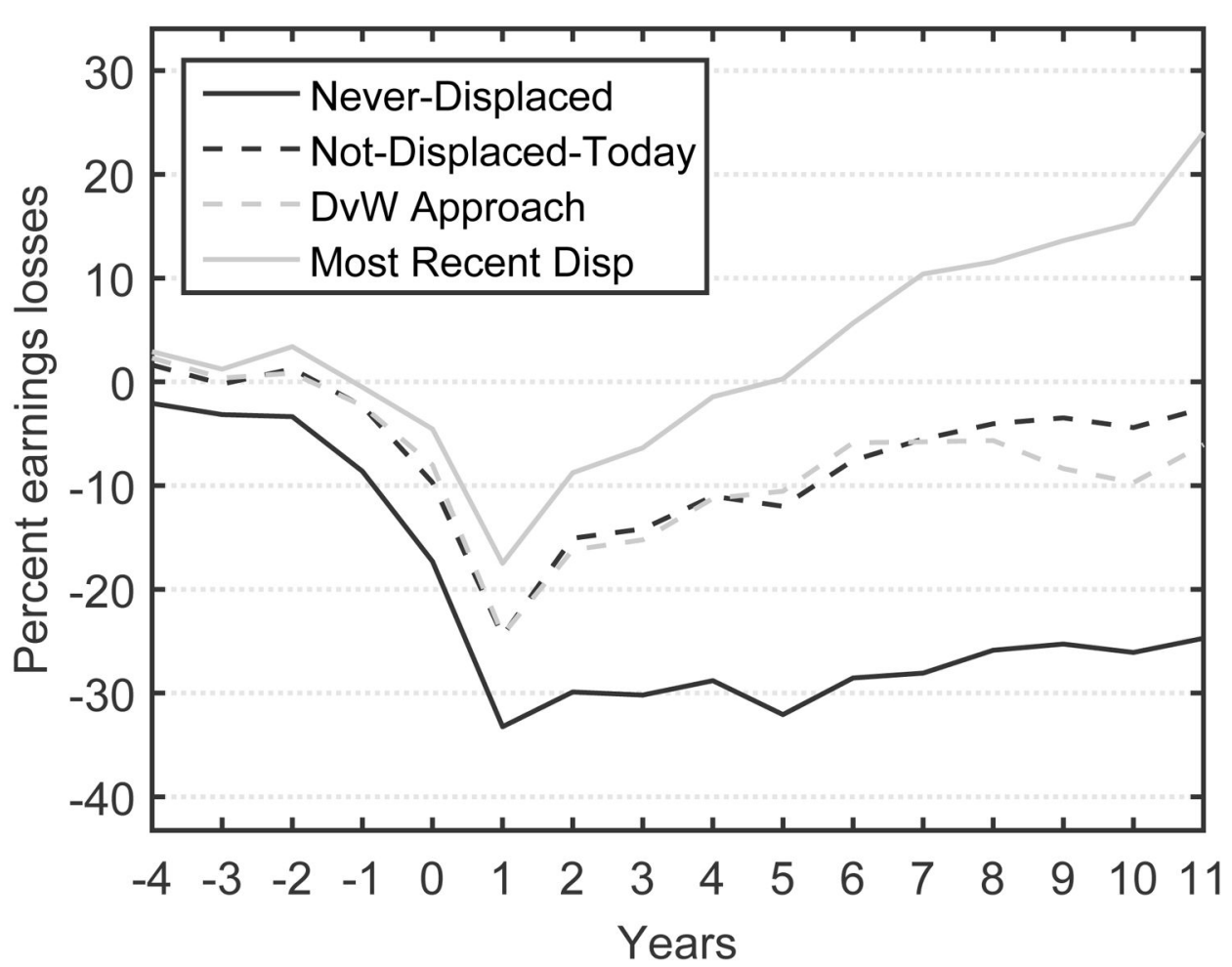

Figure 8.

Effect of Displacement on Head's Income in the PSID: Four Different Approaches Note: Using PSID data, the approach in Davis and von Wachter (2011) yields similar earnings losses to the not-displaced-today approach of this paper. Earnings losses since the most recent displacement are substantially smaller than the not-displaced-today approach and this difference becomes pronounced more than five years after the displacement event. Ten years after the displacement event, the approach that uses the most recent displacement suggests earnings gains of around 20 percent. I present the estimates from the neverdisplaced and not-displaced-today approaches from Figure 5 for reference. 


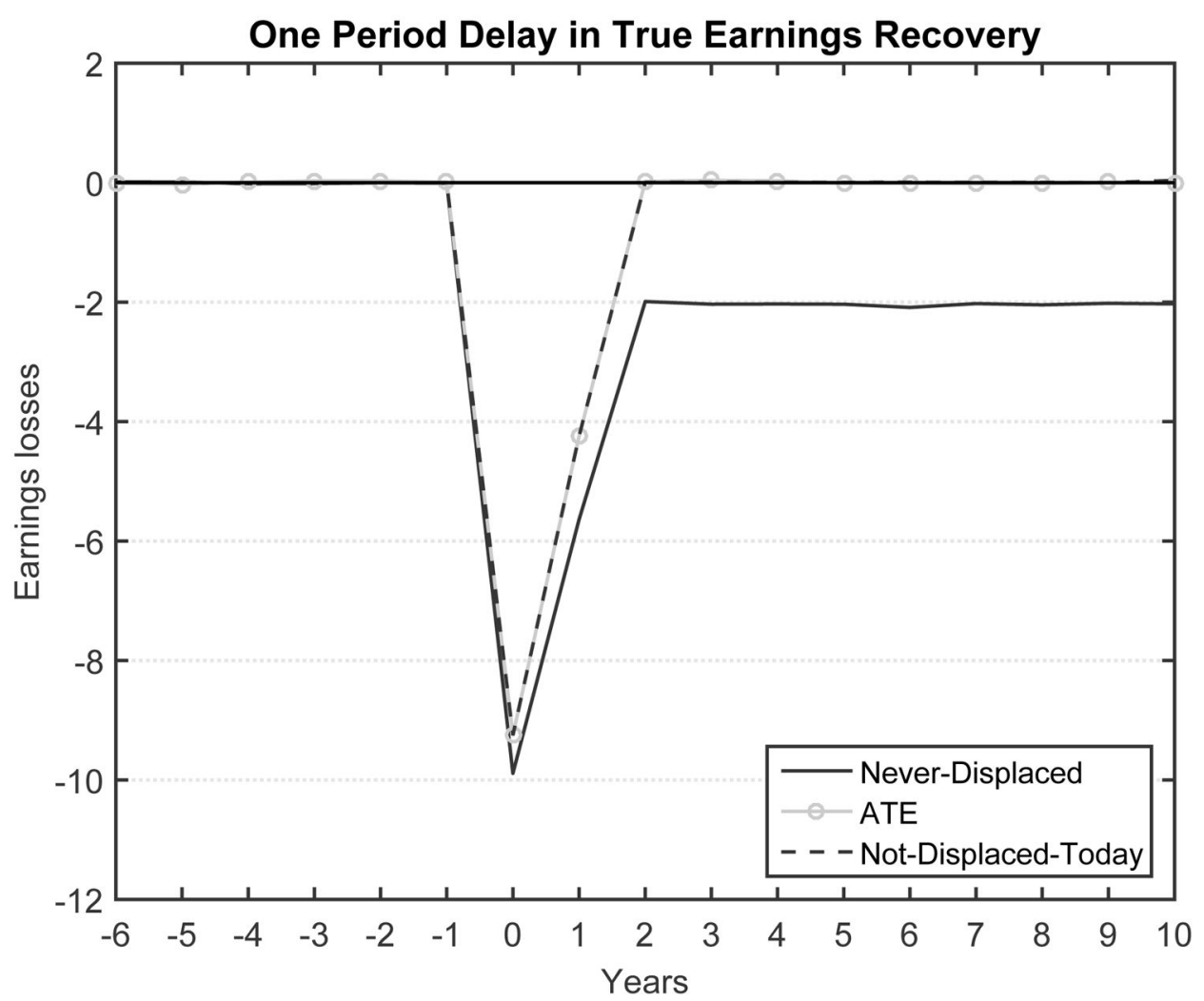

Figure 9.

One-Period Delay in True Earnings Recovery

Note: In the example where the true earnings recovery takes one period (Appendix B.1), the never-displaced approach overstates the long-run earnings losses by $-0.5 w \delta(3-\delta)=-2.14$. The not-displaced approach correctly predicts an on-impact effect of $-\mathbb{E}[\mathrm{w} / \mathrm{emp}]=-9.25$ and long-run earnings losses of zero. 


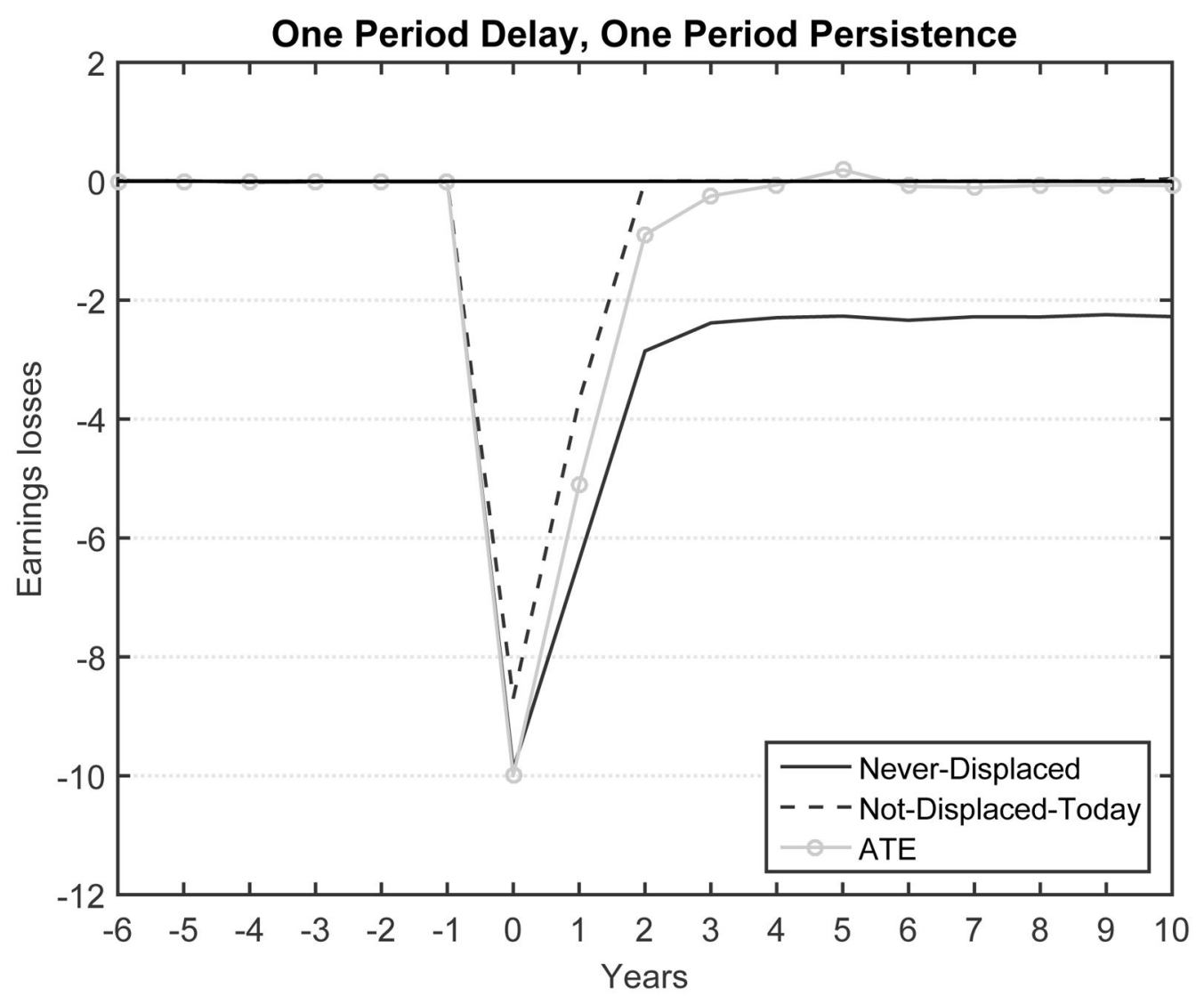

Figure 10.

Simulation with Persistent Earnings and Displacement Probability Effects

Note: In the example where earnings take one period to recover and the displacement probability is elevated for one period (Appendix B.2), the never-displaced approach overstates the long-run earnings losses. The not-displaced-today approach understates the earnings losses on impact and in the first few years after the displacement event. It correctly predicts no earnings losses in the long run. 


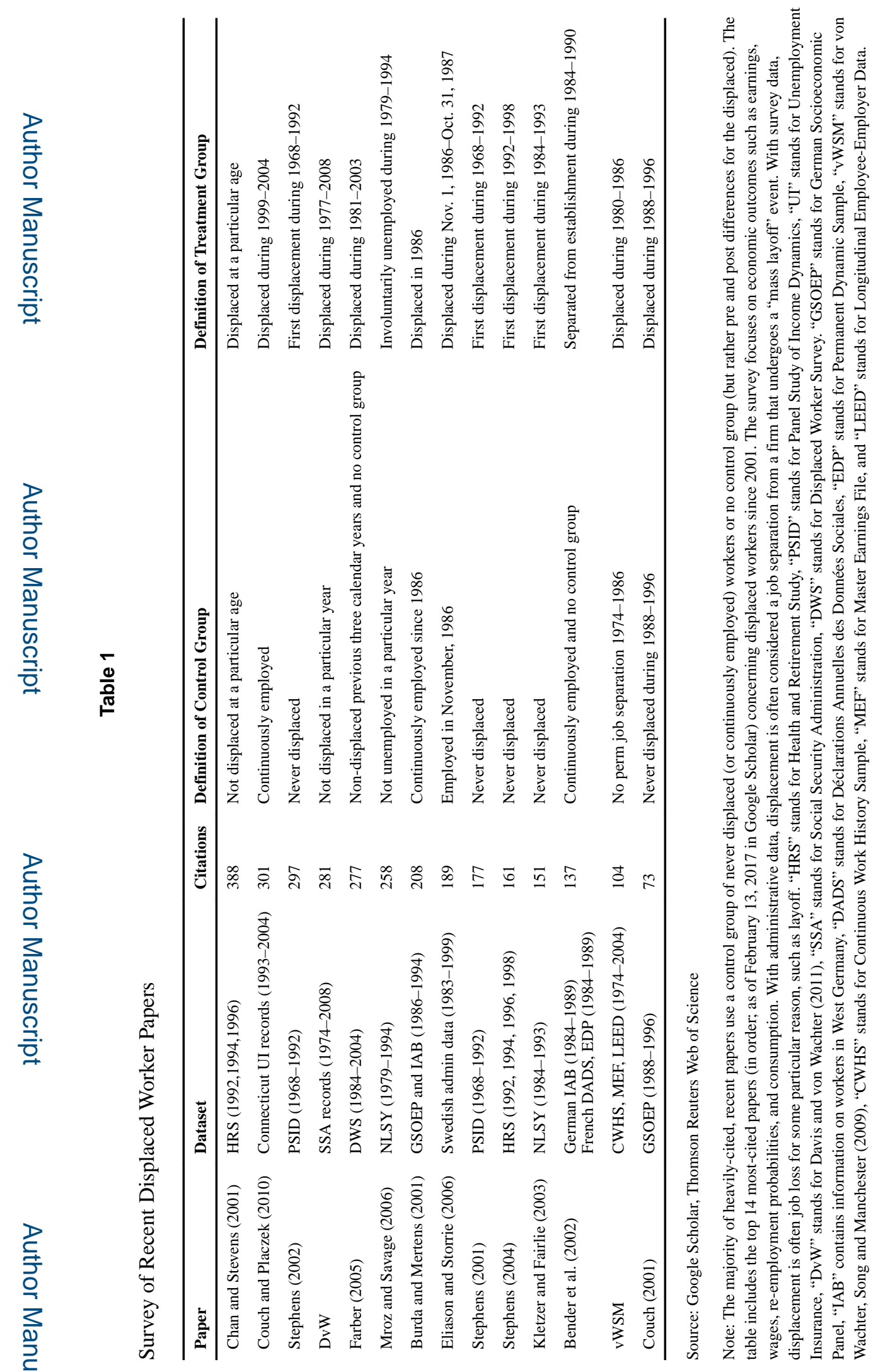

Ind Labor Relat Rev. Author manuscript; available in PMC 2019 October 01. 
Table 2

Summary Statistics

\begin{tabular}{lccc}
\hline & Never Displaced & First Displacement & Any Displacement \\
\hline Fraction male & 0.75 & 0.74 & 0.78 \\
Head's age & 42.0 & 34.4 & 35.8 \\
Head's annual earnings (\$) & 51,100 & 39,658 & 36,413 \\
Head's hourly earnings (\$) & 26.9 & 20.3 & 19.2 \\
Fraction of household heads & 59.2 & 40.8 & 40.8 \\
\hline
\end{tabular}

Note: Weighted tabulations using unbalanced data from the 1968-2009 PSID surveys. Dollar figures are in 2007 dollars using the CPI-U-X1. Averages for the never displaced individuals are calculated using every observation for these individuals. Averages for displaced individuals are calculated using the observation from the year of the shock. Pre-displacement wages and earnings are taken from two years prior to the shock. 